\title{
Can in-store displays improve category sales and brand market share in online stores? A study on overall effectiveness and differences between display types in an online FMCG context
}

Citation for published version (APA):

Breugelmans, E., \& Campo, K. (2008). Can in-store displays improve category sales and brand market share in online stores? A study on overall effectiveness and differences between display types in an online FMCG context. METEOR, Maastricht University School of Business and Economics. METEOR Research Memorandum No. 036 https://doi.org/10.26481/umamet.2008036

Document status and date:

Published: 01/01/2008

DOI:

10.26481/umamet.2008036

Document Version:

Publisher's PDF, also known as Version of record

Please check the document version of this publication:

- A submitted manuscript is the version of the article upon submission and before peer-review. There can be important differences between the submitted version and the official published version of record. People interested in the research are advised to contact the author for the final version of the publication, or visit the DOI to the publisher's website.

- The final author version and the galley proof are versions of the publication after peer review.

- The final published version features the final layout of the paper including the volume, issue and page numbers.

Link to publication

\footnotetext{
General rights rights.

- You may freely distribute the URL identifying the publication in the public portal. please follow below link for the End User Agreement:

www.umlib.nl/taverne-license

Take down policy

If you believe that this document breaches copyright please contact us at:

repository@maastrichtuniversity.nl

providing details and we will investigate your claim.
}

Copyright and moral rights for the publications made accessible in the public portal are retained by the authors and/or other copyright owners and it is a condition of accessing publications that users recognise and abide by the legal requirements associated with these

- Users may download and print one copy of any publication from the public portal for the purpose of private study or research.

- You may not further distribute the material or use it for any profit-making activity or commercial gain

If the publication is distributed under the terms of Article 25fa of the Dutch Copyright Act, indicated by the "Taverne" license above,

Download date: 26 Apr. 2023 


\section{Els Breugelmans, Katia Campo}

Can in-store displays improve category sales and brand market share in online stores? A study on the overall effectiveness and differences between display types in an online FMCG context

$\mathrm{RM} / 08 / 036$

JEL code: M31

\section{METEबR}

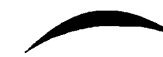

Maastricht research school of Economics of TEchnology and ORganizations

Universiteit Maastricht

Faculty of Economics and Business Administration P.O. Box 616

NL - 6200 MD Maastricht

phone : ++31433883830

fax : ++31433884873 


\title{
Can in-store displays improve category sales and brand market
}

\author{
share in online stores? A study on the overall effectiveness and \\ differences between display types in an online FMCG context
}

\author{
Els Breugelmans ${ }^{1}$ \\ Maastricht University
}

\section{Katia Campo}

Catholic University Leuven

Keywords: in-store displays, online grocery shopping, market response analyses

Acknowledgments

The authors thank Bram Foubert, Els Gijsbrechts and Michael Trusov for their helpful suggestions on previous versions of this article.

\footnotetext{
${ }^{1}$ Corresponding Author: Els Breugelmans is Assistant Professor at the Faculty of Applied Economic Sciences, Department of Marketing, Maastricht University. Address: P.O. Box 616, 6200 MD Maastricht (The Netherlands). Tel. +31433883855; Fax. +31433884918. E-mail: e.breugelmans@mw.unimaas.nl

Katia Campo is Associate Professor of Marketing at the Faculty of Business and Economics of the Catholic University of Leuven. Address: Naamsestraat 69, 3000 Leuven (Belgium). Tel. +3216326819; Fax.+3216326732. E-mail: katia.campo@econ.kuleuven.be
} 


\title{
Can in-store displays improve category sales and brand market
}

\section{share in online stores? A study on the overall effectiveness and differences between display types in an online FMCG context}

\begin{abstract}
Our study investigates the overall effects of in-store displays (ISD) on category sales and brand market share in an online shopping context, and compares the differences in effectiveness between ISD types. Using data from an online grocer, we examine three online ISD types that match with traditional ones: first screen (entrance), banner (end-of-aisle) and shelf tag (in-aisle) displays. Empirical results for 10 categories confirm that online ISD may substantially increase brand market share and to a lesser extent, category sales. Our results also demonstrate that not all types are equally effective. First screen displays clearly have the strongest effect on market share: they benefit from their placement on the 'entrance' location, central on-screen position and direct purchase link. While they only feature 1 SKU, banner displays typically feature all SKUs of a brand, yet, are placed on border-screen positions on traveling-zone pages without a direct purchase link. Based on our results, the advantage of banner displays does not weigh up against the advantages of first screen displays in most cases. Shelf tags, finally, may be very useful in attracting attention to interesting promotions, but appear to have no or at most a limited effect on their own.
\end{abstract}




\section{Can in-store displays improve category sales and brand market}

\section{share in online stores? A study on the overall effectiveness and differences between display types in an online FMCG context}

\section{INTRODUCTION}

In-store displays (ISD) are frequently used in brick-and-mortar (B\&M) stores to bring products to the attention of potential customers. Drawing attention to specific products at the point of purchase is especially important in low involvement purchase situations (e.g. when buying FMCG products), where purchase decisions tend to be made in the store based on simple decision rules (Chandon et al. 2007; Drèze, Hoch, and Purk 1994; Hoyer 1984).

Previous research within the B\&M setting has confirmed that ISD can positively affect category purchase as well as brand choice decisions (Bemmaor and Mouchoux 1991; East, Eftichiadou, and Williamson 2003; McKinnon, Kelly, and Roison 1981). The question remains whether this also holds in an online shopping context. On the one hand, there are indications that some of the traditional product presentation effects (e.g. shelf position) might be less important in online stores due to differences in shopping environment (e.g. all products placed at eye-level). Yet, on the other hand, a couple of studies have demonstrated that in-store merchandising instruments may still play an important role in catching the online shopper's attention and influencing his/her purchase decisions (e.g. Breugelmans, Campo, and Gijsbrechts 2007; Vrechopoulos et al. 2004).

A second important question resides in the fact that most academic researchers have ignored the differences in effectiveness across different ISD types. While most previous studies point to a substantial and positive sales effect of ISD, there are some studies which found no or a 
much weaker brand sales effect (Kumar and Leone 1988; Vilcassim and Jain 1991). In practice, it is a generally accepted fact that certain types of ISD work better than others (see commercial applications at www.instoremarketer.org; www.popai.com; Liljenwall 2004; Spaeth 2004). In academic research, however, differences in effectiveness between different ISD types did not receive the same attention and a systematic analysis and explanation of these differences is still lacking.

This research offers a first step in closing this gap and contributes to a better understanding of ISD effectiveness in several ways. First, we examine the overall effects of ISD on category sales (primary demand) and brand market share (switching) in an online shopping context. Comparable to B\&M stores, online (grocery) stores try to grab customers' attention via ISD to stimulate purchases of specific products (see e.g. www.netgrocer.com, www.peapod.com,

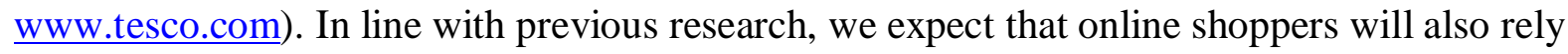
on in-store cues to facilitate their purchase decisions and to cope with the informationoverload characterizing the online shopping environment. Gaining a better insight in the overall impact of online ISD will help manufacturers to make more informed decisions on whether to use them.

Second, a major objective of this paper is to provide a better insight into the differences in effectiveness across different ISD types. By investigating three different online ISD types which are most frequently used in practice and differ on important characteristics, this study is among the first academic attempts to systematically investigate the differences in impact of different ISD types on brand market share and category sales. Insight into these differences and their determinants may provide useful guidelines to further assist manufacturers in their decision on which ISD type to select. 
Third, while our empirical analysis is limited to online ISD for FMCG, we do examine ISD effects for 10 different product categories within this group. Previous research has shown that the magnitude of the sales increases caused by ISD might depend on the product category that is featured (e.g. Curhan 1974). By investigating ISD effects for several product categories, we construct a more robust test and allow for a more accurate assessment of the overall online ISD effectiveness as well as the differences in effectiveness between ISD types.

In the next section, we first discuss the overall effectiveness of online ISD and its underlying reasons. Afterwards, we continue with building our expectations on the differences in effectiveness of different ISD types. To do so, we start with a brief description of the major online ISD types (first screen, banner and shelf tag displays), and give an overview of the display characteristics that may affect their ability to attract attention. In section three, we describe our empirical setting and introduce the models we used to test the effectiveness of different online ISD types. After giving an overview of our results, we end with a discussion and some indications for future research.

\section{EFFECTIVENESS OF ONLINE ISD}

\section{Overall effectiveness of online ISD}

In general, the main mechanism underlying category sales and brand switching effects of ISD can be found in an increase in visual attention at the point-of-purchase for the featured product (Chandon et al. 2007). In addition, many customers seem to interpret ISD as signals or cues that indicate a good deal (Inman, McAlister, and Hoyer 1990). As a result, ISD tend to affect purchase behavior, especially in low involvement, repeat buying situations, e.g. when purchasing FMCG. Previous research has shown that, in such situations, customers do not go 
through a complete search and evaluation procedure but tend to settle for satisfying rather than optimal purchase decisions, thereby relying on cues such as ISD that simplify their decision (Hoyer 1984; Inman, McAlister, and Hoyer 1990).

We expect a similar effect of ISD on consumers' purchase behavior in an online context for several reasons. First, internet buyers are typically convenience-oriented shoppers who want to save time and effort, or simply dislike shopping (Breugelmans, Campo, and Gijsbrechts 2006/2007). The use of cues, such as ISD, may help to simplify and shorten their shopping task. Second, online grocery stores are characterized by a similar information overload as B\&M stores: in almost every category, customers must choose among a large number of items while they also have the possibility to retrieve additional product information. For these reasons, we expect that also online shoppers are susceptible to in-store incentives which attract their attention and facilitate the search and decision process. We therefore expect that in general - online ISD will have a positive effect on brand market share as well as category sales.

\section{Differences in effectiveness between online ISD types}

While differences in effectiveness across different ISD are widely recognized in commercial applications (www.instoremarketer.org; www.popai.com; Liljenwall 2004; Spaeth 2004), few academic articles exist that systematically investigate the effect of different ISD types. To derive expectations on the differences in effectiveness between ISD types, we therefore also rely on related literature where similar visual attention effects are examined. More in particular, we use insights obtained from the shelf and store layout literature and from the print advertisement literature (e.g. within-medium or on-page positions). In the next section, we first give a brief description of the three online ISD types we investigate in this research. 
After a discussion of the ISD characteristics that may affect ISD effectiveness, we derive conclusions on the expected differences in effectiveness between ISD types.

\section{Online ISD types: first screen, banner and shelf tag displays}

Traditional B\&M stores typically use the store location as the categorization dimension to distinguish between ISD types (Tellis 1998). In this research, we rely on a similar locationbased classification. Online (grocery) stores are typically organized in a hierarchical way: store department pages (such as beverages) are followed by product group pages (such as soft drinks), and category list pages (such as the coke page with a list of available SKUs in that category). In what follows, we refer to this hierarchy as higher and lower level pages in the online store. The types of ISD that are typically placed at these different online store pages are very similar to the ISD types used in different locations of B\&M stores: traditional (i) entrance, (ii) end-of-aisle, and (iii) in-aisle displays translate to online (i) first screen, (ii) banner, and (iii) shelf tag displays. A graphical representation of these ISD types can be found in Appendix $\mathrm{A}^{2}$.

First screen displays are placed at higher level store department pages, typically at mid-screen positions and with a small number of ISD for brands of different product categories. Banner displays are placed on mid-level product group pages that customers need to pass when moving from department to category list pages, at border-screen positions (e.g. the top or the side of the page). In contrast to first screen displays, they do not provide a direct purchase opportunity (buy button) but a link to a separate brand-based webpage where all SKUs of the advertised brand are displayed. Shelf tag displays, finally, are placed at the center of lower level category list pages and typically occur for several brands simultaneously. They are used

\footnotetext{
${ }^{2}$ The appendix shows how the three ISD types were operationalized by the online retailer of our study. Although small differences exist in how other online grocery retailers use the different ISD types, there is quite some similarity between our online grocery retailer and other online grocery stores.
} 
in the same way as traditional store shelf tags: they are special messages in the category list used to announce sales promotions and placed right beside the promoted SKU within the virtual shelf.

\section{ISD characteristics and their impact on the effectiveness of different ISD types}

To obtain a better insight into the reasons why different ISD types may have a different impact on category sales and brand market share, we first identify the characteristics that are most likely to influence a display's ability to attract customer attention (see Figure 1). Online ISD types that are more successful in catching customer attention can be expected to have a stronger impact on the consumer's purchase behavior (Chandon et al. 2007). Based on previous advertising and in-store merchandising studies, the effect of ISD on customer attention may depend on: (1) the sequence in which a display is encountered, (2) the functionality of the store zone where it is placed, (3) the visibility (as determined by its size and on-screen position), and (4) the exclusivity or absence of 'clutter' (i.e. competition of ISD of alternative brands which are placed in the same store location). As indicated in Figure 1, these four characteristics may determine to what extent ISD succeed in attracting customer attention. In addition, whether an increase in customer attention will result in a change in purchase behavior may depend on a fifth characteristic: the ISD's actionability or the possibility to buy the featured product immediately by means of a direct purchase link. We will discuss each of these factors and their effect in more detail below.

$$
\text { <insert Figure 1> }
$$

We first examine expected effects on brand market share and category sales for each of the five ISD characteristics separately. Because the expected direction of the effect on brand market share and category sales is usually the same, we only discuss market share and category sales effects separately when differences in direction are expected. In Table 1, we 
give a summary of these expected effects (part a) as well as a classification of our three ISD types on each of the characteristics (part b). Next, we will derive expectations on the differences in ISD effectiveness by combining the insights on each of the characteristics that make up an ISD type.

\section{<insert Table 1>}

(1) Sequence. The sequence in which an ad/display is encountered, may have an important impact on the extent to which it attracts customer attention. In this respect, most previous studies provide evidence of a primacy effect: first encountered ads/displays (e.g. cover page position for printed ads; store entrance and end-of-aisle for ISD) typically reach a larger number of potential customers than later displayed ones (East, Eftichiadou, and Williamson 2003; Rossiter and Percy 1998) ${ }^{3}$. In online stores, the sequence in which displays are encountered depends on the level in the webpage hierarchy where they are placed. Online ISD presented on higher level pages (such as first screen displays on store department pages) are encountered earlier and may for this reason generate a stronger effect on category sales and the brand's market share. In addition to stimulating unplanned category purchases, they may also encourage brand switching by highlighting a specific brand in an early stage of the purchase process. Preliminary evidence of such primacy effects in an online grocery shopping context has been provided by Breugelmans, Campo, and Gijsbrechts (2007), who demonstrate that earlier encountered products have a higher probability of being chosen.

(2) Functionality. Recent in-store merchandising studies have pointed to potential differences in functionality between different store locations which may lead to differences in purchase behavior (East, Eftichiadou, and Williamson 2003; Larson, Bradlow, and Fader 2005). While

\footnotetext{
${ }^{3}$ Note that we concentrate on purchase behavior reactions, and not on cognitive/attitudinal effects such as ad recall for which some studies also found evidence of a recency effect (Pieters and Bijmolt 1997). Especially in the low involvement context where consumers seek a satisfying, effortless solution, and tend to conclude their search process as soon as they find a suitable product, primacy effects seem to outweigh recency effects (Breugelmans, Campo, and Gijsbrechts, 2007).
} 
some store zones are more used for traveling (higher level department and product group pages, which mainly direct customers to the searched for product category), other zones are merely used for shopping (lower level category pages, which provide a list of products and product specific information such as prices). As a consequence, the attention customers pay to displays may differ between store locations. Whereas displays placed in traveling zones may be passed by without being noticed or receiving much attention, customers may spend more time and effort in examining products - and hence ISD - in shopping zones containing products they planned to purchase (Larson, Bradlow, and Fader 2005). This may lead to more focused attention and a stronger impact on category sales and brand market share for ISD (such as shelf tags) at lower level pages.

(3) Visibility. Previous research has demonstrated that ads/displays that are more visible either through a more prominent position (e.g. eye/hand level shelf position) or a larger size (e.g. ad size, or number of facings in the shelf) - are more likely to catch attention and influence purchase decisions (Chandon, Chtourou, and Fortin 2003; Desmet and Renaudin 1998; Drèze, Hoch, and Purk 1994; East, Eftichiadou, and Williamson 2003; Lohse 1997). While there are some indications that online shelf positions might be less important in virtual stores - all products being placed at 'eye-level' (Breugelmans, Campo, and Gijsbrechts 2007) - there are also reasons to expect that on-screen positions of displays may still have a significant effect on their ability to attract customer attention. Customers seem to have prior expectations on where the most relevant information can be found: for print and online media, this is usually the central position. Based on the Elaboration Likelihood Model and related literature (Howard and Kerin 2006; Petty and Cacioppo 1986), we expect that online grocery shoppers, which are typically goal-directed, will focus on these central positions rather than on design elements that are not part of the main page (Cho and Cheon 2004). We therefore 
expect a more positive effect on brand market share and category sales for displays placed at the center of the page (such as first screen and shelf tag displays) compared to displays placed at border-screen positions (such as the banner display).

In addition, visibility may depend on display size: larger displays attract more attention than smaller ones and, for this reason, have a stronger effect on brand market share and category sales. For most online (grocery) stores, the size of online ISD differs between display types: ISD placed on higher level pages in the hierarchy (such as first screen and banner displays) typically receive much more space than ISD placed on lower level pages (such as the shelf tag display).

The ultimate effect of visibility is therefore to some extent inconclusive and depends on the exact size and position of the ISD. Overall, we expect that ISD that outperform other ISD on both dimensions (i.e. larger and better position) will be most visible. Compared to shelf tag displays, first screen displays have a larger size and are placed on a more prominent position. While there is no substantial difference in display size between first screen and banner displays, first screen displays have the advantage of being placed at more prominent midscreen positions, thereby increasing their visibility compared to banner displays. The difference in visibility between shelf tag and banner displays is not clear since we cannot determine in advance if smaller ISD on more prominent on-screen positions (the shelf tag display) will be more visible than larger ISD on border-screen positions (the banner display).

(4) Exclusivity. Ads/displays have been shown to have a stronger impact when there is less 'clutter', i.e. when ads/displays are more exclusive and fully capture customers' attention which is a function of the number of simultaneously placed ads/displays (Anderson and Simester 2001; Cho and Cheon 2004). Anderson and Simester (2001) have shown that displays are less effective in increasing market share when more products have them. The 
number of displays for directly competing brands (i.e. brands from the same category) is usually much smaller at higher level pages which often contain a number of displays for different product categories but highlight only one brand for a given category. Lower level pages, in contrast, very often contain (shelf tag) displays of many different, directly competing brands. Hence, we expect that more exclusive brand displays at higher level pages (first screen and banner displays) may generate stronger brand market share effects than (shelf tag) displays placed at lower level pages. Demand on the category sales level, however, appears to be maximized when some but not all products carry a display. While more displays entail a stronger impact on category sales, this positive display effect is eventually outweighed by the loss of credibility when too many products have such a display, leading to an inverted U-shaped relationship between the number of displays and the level of category sales (Anderson and Simester 2001).

(5) Actionability. Because of the unique interactive characteristics of online ISD, we add a fifth determinant which we refer to as actionability. While some ISD provide direct purchase opportunities (first screen and shelf tag displays: buying by clicking on the purchase button), other ISD types (the banner display) provide a link to another webpage where customers can find more information and/or select a product from a specific (in most cases brand-based) product list. In low involvement situations where consumers do not go through a complete and thorough evaluation procedure but rather try to minimize their search effort, we expect that direct purchase links will generate a stronger effect on market share and category sales than indirect links. When a display succeeds in drawing the attention, the possibility to react immediately can be expected to reinforce the positive effect of increased attention on category sales and brand market share. 
By combining the insights on each of the characteristics that make up an ISD type, we can derive expectations on the differences in ISD effectiveness. We expect the strongest effect for first screen displays, at the category sales as well as the brand market share level: first screen displays are encountered earlier, are more visible (mid-screen position, medium to large size), and provide a direct link to purchase the product. What is more, at the market share level, they have the additional advantage of being exclusive by featuring only one brand of a specific category. When comparing shelf tag and banner displays, there are both positive and negative signs: while banners are larger in size, are encountered earlier and usually do not face any competition of other brand banners, shelf tags are typically placed at more prominent midscreen positions in the shopping zone and provide a direct purchase opportunity. Because of these contradictory underlying effects, we cannot determine in advance which of these two ISD types is more effective. Yet, by testing ISD effects for 10 different product categories, the results may provide further indications on which display characteristics play the most important role and which ISD type (banner versus shelf tag display) can be expected to be most effective.

\section{DATA AND MODELS}

\section{Data}

We obtained market share and category sales data of a major online grocery store, for a 26month period (120 weeks) and 10 product categories. For the same store, categories and time period, we also have detailed information on online ISD campaigns and promotional actions. First screen, banner and shelf tag displays are renewed on the first of each month. Table 2 gives an overview of the different ISD occurrences for the 10 categories, revealing substantial variation in ISD types and category penetration/purchase frequency (captured by the category's position in the top based upon sales). 
<insert Table 2>

\section{Models}

Given the potentially differential effects of online ISD on category sales and brand market share and based on the market response modeling literature (e.g. Hanssens, Parsons, and Schultz 2001), we model brand sales as the product of its market share and category sales. As explained in more detail below, we also take effects at the SKU level into account by using a hierarchical market share model.

\section{The category sales model}

The impact of ISD variables on overall weekly category sales is assessed by a multiplicative regression model with overall category sales as dependent variable $\left(\right.$ CatSales $\left._{t} ; \mathrm{t}=1, \ldots, \mathrm{T}\right)$. The model takes the following form:

$$
\text { CatSales }_{t}=e^{\alpha_{c}} \prod_{m=1}^{M} e^{\delta_{m} X_{m, t}} \text { CatSales }_{t-1}^{\delta_{\text {lag } C S}} \prod_{h=1}^{H} e^{\chi_{h} D_{h t}}
$$

where $D_{h t}$ are seasonal dummies, $h(1, \ldots, \mathrm{H})$ is the index for holiday and special event periods, CatSales ${ }_{t-1}$ is the lagged effect of sales, $X_{m, t}$ captures the effects of marketing mix variables (the relevant ISD types) at the category level, and $\alpha_{c}, \delta_{m}, \delta_{\text {lagCS }}, \chi_{h}$ are parameters to be estimated. An overview of the symbols is given in Table 3. We convert this model into an equivalent linear model via the logarithm transformation.

<insert Table 3>

We include the following marketing mix variables: a first screen display variable $F S_{t}$, a banner display variable $B A N_{t}$ and shelf tag display variables. In our empirical setting, shelf tags are exclusively used as promotion signals. This has two important implications. First, it is not feasible to estimate a 'pure' shelf tag effect, yet, shelf tags are seldom or never used on their own in practice. Second, shelf tag effectiveness may depend on the type of promotion 
that is announced. For these reasons, we include promotion-specific shelf tag variables in our model $^{4}$. Based on our data set, we identified four different promotional activities: price cuts $P C_{t}$, club points $C P_{t}$, free promotions $F P_{t}$ and premium promotions $P P_{t}^{5}$. The parameters linked to these variables allow to test whether and which ISD types have a significant impact on category sales. Note that not all of the promotional shelf tag variables are incorporated in each model specification because some categories only use a sub-set of these promotional variables during our observation period. Further note that we also did not include any price variable in the model (neither in the market share model described in the next section) because product prices remained largely the same over the considered period, and inclusion of this variable led to severe collinearity problems with the model's constant.

We further account for seasonality by using dummy variables for special periods (holidays and official events) $D_{h t}$. Based on observations of the data and managerial input, we included four dummy variables: Summer, Easter, Christmas/New Year and Mid Term vacation. Within an online grocery store, these periods are characterized as lower selling ones because customers either go on vacation (and therefore do not need the online grocery service), or stay at home but do not need to work (and therefore have time to go to the B\&M store themselves). As a consequence, we expect a negative parameter for these dummy variables. In order to ensure that our exogenously identified seasonal dummies match the data, we performed outlier analyses. In the few occasions where an additional outlier could be

\footnotetext{
${ }^{4}$ Instead of using promotion-specific shelf-tag variables, we re-ran the models with an overall shelf tag variable which captured the mere announcement of a promotion making abstraction of the specific type. For none of the category sales and market share models, the inclusion of this overall shelf tag variable improved model fit or face validity.

${ }^{5}$ We decided to use the amount of price reductions and loyalty program points for price cut and club point promotions and a dummy variable for the other two promotion types (see Table 3) because previous research has pointed out that consumers are sensitive to the (monetary) value of a promotion (DelVecchio, Krishnan, and Smith 2007). This is especially relevant for the former two promotion types. Robustness checks indeed pointed out that the usage of dummy variables for price cut and club point promotion variables, or the usage of a monetary value expression for the free promotion variable reduced model fit.
} 
identified, including this as a separate dummy variable resulted in no difference with the original model. We therefore decided to stick to our exogenously defined variables. Finally, we incorporated a lagged sales variable CatSales $_{t-1}$ to capture carry-over effects.

\section{The hierarchical market share model}

In our empirical setting and like in most other (online) grocery stores, some ISD types are defined at the brand level (banner) while others are defined at the SKU level (first screen and shelf tags). For this reason, we use a two-stage hierarchical market share model which allows to include different predictor variables defined at the brand and SKU level and to capture nonIIA competition patterns between SKUs belonging to different brands. Since the traditional attraction model is nested in the hierarchical one, it also allows for a formal test of these nonIIA competition patterns (Foekens, Leeflang, and Wittink 1997). In line with the layout of the website and the followed marketing mix strategy, we applied a brand-SKU hierarchy, which allows to estimate the effects of different ISD types at the appropriate level: the brand level for banner displays, and the SKU level for the other ISD types. We define the market share of SKU s $(1, \ldots, \mathrm{S})$ of brand $\mathrm{b}(1, \ldots, \mathrm{B})$ at time $\mathrm{t}\left(m s_{s b, t}\right)$ as:

$$
m s_{s b, t}=m s_{b, t} \times m s_{s \mid b, t}
$$

with $\quad m_{b, t}=$ market share of brand $\mathrm{b}$ at time $\mathrm{t}$;

$$
m_{s \mid b, t}=\text { market share of SKU s within brand } \mathrm{b} \text { at time } \mathrm{t} \text {. }
$$

Market share of the lowest level in our nested model can be formalized as:

$$
m_{s \mid b, t}=\frac{A_{s \mid b, t}}{\sum_{i=1}^{S} A_{i \mid b, t}}
$$

where 


$$
A_{s \mid b, t}=\exp \left[\alpha_{s}+\sum_{m_{l}=1}^{M_{l}} \beta_{m_{l}} X_{m_{l}, s b t}\right]
$$

Next to including an intercept $\left(\alpha_{s}\right)$, we also include marketing mix effects $\left(X_{m_{s} b, t}\right)$ measured at the SKU level with $\beta_{m_{l}}$ being the parameter that captures the effect of the marketing mix variable $\mathrm{m}\left(1, ., \mathrm{M}_{1}\right)$ on the (conditional) market share and where subscript 1 stands for the lower level effect. To be more specific, we include a first screen display variable $F S_{s b, t}$ and promotion-specific shelf tag variables. Like before, four different promotional activities were used which are only incorporated in the model specification when the category made use of them during our observation period: price cuts $P C_{s b, t}$, club points $C P_{s b, t}$, free promotions $F P_{s b, t}$ and premium promotions $P P_{s b, t}$.

Market share of brand $\mathrm{b}$ can be written as

$$
m_{b, t}=\frac{A_{b, t}}{\sum_{j=1}^{B} A_{j, t}}
$$

where

$$
A_{b, t}=\exp \left[\alpha_{b}+\sum_{m_{u}=1}^{M_{u}} \beta_{m_{u}} Y_{m_{u} b, t}+(1-\sigma) I V_{b, t}\right]
$$

We again include the intercept $\left(\alpha_{b}\right)$ and add marketing mix variables of brand $\mathrm{b}$ defined at the brand level $\left(Y_{m_{u} b, t}\right)$ with $\beta_{m_{u}}$ being the parameter reflecting the effect of marketing mix variable $\mathrm{m}\left(1, \ldots, \mathrm{M}_{\mathrm{u}}\right)$ on brand market share and where subscript $\mathrm{u}$ stands for the higher (upper) level effect. Given that banner ads are defined at the brand level, we include a banner display variable $B A N_{b, t}$ in equation (6) and not in equation (4). In addition, we include a first screen display variable $F S_{b, t}$ to capture additional attention-steering effects of this ISD type over 
and above the effects that emerge as a result of an increase in brand attractiveness ${ }^{6}$. The

change in brand attractiveness is measured by an inclusive value for brand $b$ defined as:

$$
I V_{b, t}=\log \left(\sum_{s=1}^{S} \exp \left[\alpha_{s}+\sum_{m_{l}=1}^{M_{l}} \beta_{m_{l}} X_{m_{l} s b, t}\right]\right)
$$

The inclusive value variable is the $\log$ of the sum of the attractions of all SKUs belonging to brand $\mathrm{b}(\mathrm{s}=1, \ldots, \mathrm{S})$. The term $(1-\sigma)$ gives an indication of the impact of the total attractiveness of the set of SKUs of brand $b$ on the brand's market share, and varies between 0 and 1 (Foekens, Leeflang, and Wittink 1997).

\section{RESULTS}

\section{The category sales model}

For the category sales model, we report the parameter estimates with their significance level in Table 4.

\section{<insert Table 4>}

Table 4 also includes the outcomes of the Stouffer combined test ${ }^{7}$ which is an overall test of the parameters (Rosenthal 1991; Wolf 1986). By using a combined test, statistical generalizations can be made with respect to the combined evidence resulting from all the estimations/categories (Wolf 1986). In addition, we accompany the combined tests with an index of effect size for each variable. This index provides us with an insight into the strength

\footnotetext{
${ }^{6}$ Since first screen displays are encountered early in the shopping hierarchy and have an exclusive nature, they can induce respondents to purchase products they did not plan to buy. Shelf tags, in contrast, only become visible in the product category's list and are not exclusive. It therefore seems reasonable to include them solely at the lowest level of the hierarchy. Yet, as a robustness check, we tested the inclusion of the shelf tag variables at both stages. There was no change in the substantive results, neither did model fit significantly increase.

${ }^{7}$ The Stouffer test, also referred to as the method of adding Z's (standard normal values), starts with finding the corresponding Z's for the one-tailed p-levels obtained for each of the estimations/categories. When effects are in the same (i.e. expected) direction, the corresponding Z's have the same sign while the signs are different if results are in the opposite direction. Subsequently, the Z's are summed and divided by the square root of the number of tests combined (in our case: the number of estimations/categories). This new $\mathrm{Z}$ follows a standard normal distribution and corresponds to the p-value that the results of the estimations/categories combined could have occurred under the corresponding null hypothesis (cf. Gijsbrechts, Campo, and Goossens 2003). Next to the Stouffer test, we also computed the Winer combined test which produced exactly the same results.
} 
of the relationship, i.e. the degree to which the phenomenon is present in the population (Wolf 1986). We first converted the t-value for each variable to the effect size index $d$ and next take the average of these effect sizes $\left(d_{a}\right)$ to represent the mean effect size across all the estimations/categories ${ }^{8}$ (Wolf 1986).

For almost all categories, we observe - as expected - a positive significant effect of the lagged sales variable and negative significant effects for the seasonal dummy variables (Summer, Eastern, New Year/Christmas and Mid Term). In addition, we find - contrary to our expectations - no or very small effects of ISD types on category sales. First, we do not find any significant positive effects of first screen displays. The Stouffer test confirms the finding of no combined effect $(\mathrm{p}>.10)$. Second, for the banner display, we find a positive significant effect for 4 categories only (mineral water, sparkling water, beer and at a $10 \%$ level also drinking yoghurt), while no significant effects could be observed for the other categories. Although the Stouffer test points to a significant positive combined effect $(\mathrm{p}<$ .01 ), the effect size index confirms that the average effect is small ${ }^{9}$ and quite some variation exists across categories (small mean .16 but relatively large standard deviation .29). Third, also the effect of shelf tag displays is limited: there is only one marginally significant positive effect for price cuts (butter), no significant effect for free promotions and only two significant positive effects for premium promotions (coke and beer). The Stouffer test for price cuts, free and premium promotions support these observations $(\mathrm{p}>.05)$. Club point promotions, in contrast, are positive and significant in a large number of categories which is confirmed by the Stouffer test $(\mathrm{p}<.01)$ as well as a medium mean effect size $(.34)$. So, the more loyalty program points that are announced via a shelf tag display, the stronger the effects on category

\footnotetext{
${ }^{8}$ As a robustness check, we re-ran the tests with the Pearson Product Moment Correlation $\mathrm{r}$ as common metric and found exactly the same results.

${ }^{9}$ Cohen (1977) provides the following guidelines for the effect size: small when $\mathrm{d}=.2$, medium when $\mathrm{d}=.5$ and large when $\mathrm{d}=.8$.
} 
sales. Overall, however, the results indicate that it is not the shelf tag but rather the promotion which is announced by it that may cause an upward shift in category sales.

\section{The hierarchical market share model}

Having identified the effects of ISD on category sales, the next step consists of estimating the effects on market share. To estimate the hierarchical market share model, we used a sequential estimation procedure: after estimating the parameters from equation (4), we calculated the inclusive value $I V_{b, t}$ from equation (7) and estimated the parameters from equation (6) given the values of $I V_{b, t}$ (Foekens, Leeflang, and Wittink 1997). Table 5 shows the estimation results. For the SKU level model, we report the number of positive, no or negative significant coefficients $(\alpha=.05)$. For the brand level model, we report the parameter estimates with their significance level. We also include for both levels of the hierarchical market share model, the Stouffer test and mean effect size index.

<insert Table 5>

At the lower level of the hierarchical market share model (the share of an SKU within a specific brand), we find a very strong, positive effect of the first screen display: in 12 out of 18 lower level estimations where a first screen display was present, the effect was positive and significant, and in none of the cases a significant negative effect could be found. What is more, for all categories, at least one of the lower level models produced a significant and positive effect for the first screen display variable. The Stouffer combined test confirms that the null hypothesis of no significant first screen display effect common to each of the estimations should be rejected $(\mathrm{p}<.01)$, and the mean effect size $(.58)$ points towards a medium effect. So, interestingly and as expected, we find that market share of an SKU within a specific brand increases when it is announced via a first screen display. 
As expected, the effect of shelf tags differs substantially depending on the type of promotion that is announced. Based on the Stouffer test, there is clearly no effect for price cuts and free promotions $(\mathrm{p}>.10)$. One possible reason might be the proliferation of these promotional campaigns in the online grocery store (see Table 2). On the other hand, club points and premium promotions do have a significant effect on market share of an SKU within a specific brand (Stouffer test: $p<.01$ ). At the same time, the number of significant coefficients across estimations remains small. For 2 out of 9 (club points) and 2 out of 6 (premium) categories, significant positive results emerge on market share when an SKU is promoted with club points or a gift, respectively. The latter observations are also supported by the small mean effect sizes with relatively large standard deviations, $.14($ s.e. $=.25)$ and $.10($ s.e. $=.27)$, for club point and premium promotions respectively.

Comparing the magnitude of shelf tag display effects with those for first screen display effects learns that, for none of the estimated models, a significant first screen display effect is outperformed by a shelf tag effect. So, even when disregarding potential additional higher order first screen effects (discussed next), we already find indications that first screen displays are more effective in stimulating market share than shelf tag displays.

Turning to the higher level of the hierarchical model (brand market share), we first observe that the inclusive value ${ }^{10}$ is significant for all categories (for mineral water at $10 \%$, for all other categories at 1\%) and has a value between 0 and 1 . For categories with a value closer to 1 (like coke, shower soap and butter), changes in the attractiveness caused for instance by first screen displays result in a stronger impact on brand market share than for categories with a value closer to 0 (like mineral water and toilet paper). Yet, even for these categories, the

\footnotetext{
${ }^{10}$ Note that we report $1-\sigma$.
} 
significant effects of ISD observed on the lower level of the hierarchy carry through via the inclusive value to the higher level. Otherwise stated, positive significant shelf tag or first screen display effects not only result in increases in market share of the SKU that is promoted but, via the higher inclusive value, also produce upward changes for the market share of the brand as a whole. The Stouffer combined test $(\mathrm{p}<.01)$ as well as the large effect size of the inclusive value (1.12) support this finding.

What is more, for a number of categories (beer and toilet paper at $1 \%$, and drinking yoghurt at $10 \%$ ), the first screen display has an additional effect on market share of the brand, over and above the effect that comes via the inclusive value. The Stouffer test produces an overall positive significant effect $(\mathrm{p}<.01)$. Nevertheless, while the mean effect size across categories is small (.23), suggesting that a change in first screen display would result in minimal increases at the brand market share, the standard deviation of .48 indicates that there is substantial variation in effectiveness of this ISD type across categories.

Finally, a banner results in an increase in attraction for a brand in 4 out of the 10 categories (mineral water, coke, drinking yoghurt and margarine). The Stouffer test indicates that banner displays produce a positive significant effect on brand market share $(\mathrm{p}<.01)$. Yet, like for the first screen variable, we find a rather small mean effect size (.20) with a relatively large standard deviation (.33).

\section{Robustness checks}

To verify the validity of our findings, we conducted several robustness checks for the category sales and market share models. For the category sales model, we estimated several alternative model specifications (linear instead of a multiplicative model, smoothed lagged 
sales instead of the simple lagged sales variable, week-based trend instead of the lagged sales variable), which did not result in significantly better estimation results. We also tested for first-order autocorrelation using the Durbin-Watson test, which did not reveal any problems. For the market share model, we estimated alternative specifications of the hierarchical attraction model, replacing the brand-SKU hierarchy by a size-SKU or flavor-SKU one, which again, in both cases, did not improve the face validity or goodness-of-fit of our results. In addition, instead of estimating a general inclusive value effect (see equation (6)), we estimated models with nest-specific inclusive value effects. Also for this check, neither face validity, nor model fit improved. Finally, we added lagged versions of the promotion-specific shelf tag variables in our model to capture possible dynamic effects. Doing so did not result in model fit or face validity improvement. Previous researchers have already indicated that dynamic promotion effects are relatively hard to capture (Chan, Narasimhan, and Zhang 2008), something that might be fortified by the aggregate nature of our data and the less stable shopping frequency pattern of online buyers.

\section{Implications for manufacturers}

Based on the equations and the estimation results presented above, we can derive insights in how manufacturers should choose among the ISD types when the objective is to maximize profit. In line with Zhang and Wedel (2008), we focus on the manufacturer's instead of the retailer's perspective for the following reasons. First, as shown in our results section, the effects of ISD on category sales - which are the primary interest of a retailer - are not significant in most cases. Second, as suggested by Zhang and Wedel (2008) and confirmed by the management of the online grocery store in our case, manufacturers are providing financial support for administering most of the in-store merchandising tools. 
A manufacturer is primarily interested in the impact ISD have on total brand sales which depends on the brand's market share as well as total category sales, i.e.

Sales $_{b, t}=$ CatSales $_{t} * m_{b, t}$. As indicated above, shelf tags have a very limited effect on market share and category sales, which is why we leave them out in the following discussion. An especially interesting issue, however, is the trade-off between first screen and banner displays: they not only differ in focus (highlighting one of the brand's SKUs vs. featuring the brand as a whole by providing a link to a special product page) but also with respect to placement costs (amount charged by the retailer to feature an ISD). For the online grocery store in our case, the placement costs of a first screen display are two third lower than the costs involved with a banner display. Starting from the assumption that the ultimate goal for a manufacturer is to improve brand sales (and not only SKU performance), we determine how and when banner or first screen displays provide the largest increase in brand sales. Below, we explore the factors that may determine the size of the brand sales effect based on the model equations. Next, we illustrate the impact of these factors using simulations and explore differences between categories, distinguishing between top and lower selling ones (respectively the first five and last five categories in Table 2). We end this section with profitability analyses where we take ISD costs into consideration.

Based on equation (1-7), we derive the percentage change in brand sales ${ }^{11}$ caused by a first screen display as:

$$
\Delta \text { Sales }_{b, t} \mid F S=\frac{\text { Sales }_{b, t} \mid F S_{b, t}-\text { Sales }_{b, t} \mid \text { noFS }_{b, t}}{\text { Sales }_{b, t} \mid \text { noFS }_{b, t}}=\left(\frac{\text { CatSales }_{t} \mid F S_{b, t}}{\text { CatSales }_{t} \mid \text { noFS }_{b, t}} * \frac{m_{b, t} \mid F S_{b, t}}{m_{b, t} \mid \text { noFS }_{b, t}}\right)-1
$$$$
=\left(\exp \left(\delta_{F s}\right) * \exp \left(\beta_{F s, u}\right) * \frac{\exp \left[(1-\sigma) * \log \left[\left(1-m_{s b, t}\right)+m_{s b, t} * \exp \left(\beta_{F s, l}\right)\right]\right.}{\left(1-m_{b, t}\right)+m_{b, t} *\left[\exp \left[\left(\beta_{F s, u}\right)+(1-\sigma) * \log \left[\left(1-m_{s b, t}\right)+m_{s b, t} * \exp \left(\beta_{F s, l}\right)\right]\right]\right.}\right)-1
$$

\footnotetext{
${ }^{11}$ We use percentage change in brand sales as a measure instead of marginal effects because both first screen and banner displays are dummy variables.
} 
and the percentage change in brand sales for banner displays as:

$$
\begin{aligned}
\operatorname{SAales}_{b, t} \mid \text { BAN } & =\frac{\text { Sales }_{b, t} \mid \text { BAN }_{b, t}-\text { Sales }_{b, t} \mid \operatorname{noBAN}_{b, t}}{\text { Sales }_{b, t} \mid \operatorname{noBAN}_{b, t}}=\left(\frac{\text { CatSales }_{t} \mid \text { BAN }_{b, t}}{\text { CatSales }_{t} \mid \text { noBAN }_{b, t}} * \frac{m_{b, t} \mid \text { BAN }_{b, t}}{m_{b, t} \mid \operatorname{noBAN}_{b, t}}\right)-1 \\
& =\left(\exp \left(\delta_{\text {Ban }}\right) * \exp \left(\beta_{\text {Ban }, u}\right) * \frac{1}{\left(1-m_{b, t}\right)+\exp \left(\beta_{\text {Ban }, u}\right) * m_{b, t}}\right)-1
\end{aligned}
$$

Comparing equation (8) and (9), we see that for both equations the first component depends on the effect of the ISD on category sales $\left(\exp \left(\delta_{F s}\right)\right.$ and $\left.\exp \left(\delta_{B a n}\right)\right)$. Based on the discussion above, we know that there are only significant effects on category sales in 4 product categories for the banner display and in none of the categories for the first screen display. The second component for both equations includes a higher level effect (brand level of the hierarchical market share model) for the first screen and banner display $\left(\exp \left(\beta_{F s, u}\right)\right.$ and $\left.\exp \left(\beta_{B a n, u}\right)\right)$, and a lower level effect (SKU level) for the first screen display only $\left(\exp (1-\sigma) * \log \left[\left(1-m_{s b, t}\right)+m_{s b, t} * \exp \left(\beta_{F s, l}\right)\right\rfloor\right)$. For categories where the banner coefficient parameter is significant, we observe in our estimation results a much smaller higher level effect for first screen displays (Table $5, \beta_{B a n, u}>\beta_{F s, u}$ ). Although this might lead to the conclusion that banner displays are more interesting for manufacturers, the global effect for first screen displays depends on the lower level effect as well. The latter is a function of the following three components: (i) the attractiveness of the SKU that is featured $\left(m_{s b, t}\right)$, (ii) the lower level effect of first screen displays $\left(\beta_{F s, l}\right)$, and (iii) the responsiveness of the brand market share to changes in brand attractiveness $(1-\sigma)$. Even when the higher level banner effect is larger than the higher level first screen effect, the global effect of first screen displays can still be equal to or even be larger than the global effect of banner displays. Based on the previous derivations, we know that this is the case when an attractive SKU of a brand with high marketing effort effectiveness $\left((1-\sigma) * \beta_{F s, l}\right)$ is featured via a first screen display. Note 
that when first screen displays do not change within-brand market share of the featured SKU $\left(\beta_{F s, l}=0\right)$ and/or changes in within-brand SKU attractiveness do not work through to the higher brand level $((1-\sigma)=0)$, equation (8) reduces to the same form as equation (9) with only a category sales and a higher level first screen effect on brand market share.

Finally, both equations include a correction factor (the denominator) that penalizes the effect of ISD for brands that already have a relatively high market share (captured by $m_{b, t}$ ). Brands with a lower market share, on the other hand, have more to gain from highly effective ISD (i.e., a first screen display with a large higher and lower level effect, captured by $\exp \left[\left(\beta_{F s, u}\right)+(1-\sigma) * \log \left[\left(1-m_{s b, t}\right)+m_{s b, t} * \exp \left(\beta_{F s, l}\right)\right]\right]$ and a banner display with a large higher level effect, captured by $\left.\exp \left(\beta_{\text {Ban, }}\right)\right)$.

To illustrate the impact of the above-mentioned factors, we ran simulations based on the actual marketing environment (see Table 6).

\section{<insert Table 6>}

First, simulation results show that category sales are in most cases not affected when an SKU is promoted with a first screen display (cf. Table 4, no significant effects of the first screen display) or banner display (no significant effect for 6 out of the 10 product categories). When significant (4 out of the 10 product categories), banner displays provide an increase in category sales between $13.40 \%$ and $17.87 \%$.

Second, results show that the average percentage increase in brand market share caused by a first screen (banner) display amounts to $16.65 \%$ (9.09\%), with $0.68 \%(0.44 \%)$ being the minimum increase and $106.29 \%(33.67 \%)$ being the maximum increase observed when the ISD was significant. For 4 categories we observed a significant lower level first screen as well as a significant higher level banner display effect (see Table 5: mineral water, coke, drinking yoghurt and margarine), allowing for a direct comparison of first screen and banner effects 
within the same category. For 2 of these categories (coke and drinking yoghurt), a first screen display results in a higher increase in brand market share than a banner display. In line with our discussion above, these 2 categories have a high marketing effort effectiveness (relatively large IV-coefficients $(1-\sigma)$ and lower level first screen coefficients $\beta_{F s, l}$ ) while the other 2 categories (mineral water and margarine) have a lower marketing effort effectiveness (relatively small IV-coefficients $(1-\sigma)$ and lower level first screen coefficients $\beta_{F s, l}$ ). The simulation results also show that among categories with a similar marketing effort effectiveness, the largest increase in brand market share coming from a first screen display is generated by SKUs with a high market share $m_{s b, t}$ (e.g. for Brand 1 in the toilet paper category, the impact of the first screen display on brand market share is $27.38 \%$ higher when the more attractive SKU1 is featured than when the less attractive SKU9 is featured). Finally, simulation results confirm that \% increases in brand market share are lower for brands with high compared to low market share $m_{b, t}$ (e.g. the increase in brand market share within the drinking yoghurt category is $14.03 \%$ higher for Brand 1, the less popular brand, than for Brand 2, the more popular brand).

Taking both market share and category sales effects into consideration, results at the brand sales level indicate that both ISD types have the potential to be effective. First screen displays as well as banner displays may significantly increase brand sales: on average and across all cases, they generate additional sales worth $215.35 €$ and $380.47 €$ respectively. The wide range of observed brand sales effects, however, indicates that there exists quite some variation in the magnitude of the effect across categories. Comparing top and lower selling categories (first five vs. last five categories of Table 2) learns that the former are far more successful in generating sales increases than the latter: $307.23 €$ vs. $31.53 €$ for first screen displays, and $597.26 €$ vs. $39.80 €$ for banner displays. 
To evaluate ISD effects, manufacturers should not only look at increases in brand sales, but also need to take the costs of the respective ISD into consideration. On average, the estimated brand sales increase of banner displays is 1.77 times larger than the brand sales increase caused by first screen displays ${ }^{12}$. As indicated before, this does not necessarily mean that banner displays are more profitable than first screen displays: next to the brand's profit margin $\left(\pi_{b}\right)$, the overall profit increase generated by an ISD for brand $\mathrm{b}\left(\Pi_{b}\right)$ also depends on the costs involved for placing and administering banner and first screen displays ${ }^{13}$ $\left(\right.$ Costs $_{B A N}$ or Costs $\left._{F S}\right)$ :

$$
\begin{aligned}
\Pi_{b} \mid F S & =\left(\left(\text { Sales }_{b} \mid F S-\text { Sales }_{b} \mid \text { noFS }\right) * \pi_{b}\right)-\text { Costs }_{F S} \\
\Pi_{b} \mid \text { BAN } & =\left(\left(\text { Sales }_{b} \mid \text { BAN }- \text { Sales }_{b} \mid \text { noBAN }\right) * \pi_{b}\right)-\text { Costs }_{B A N}
\end{aligned}
$$

We illustrate the trade-off between banner and first screen displays with the following simple example. For the known cost difference $\left(\operatorname{Cost}_{B A N}=3 * \operatorname{Costs}_{F S}\right)$ and estimated difference in brand sales effects (additional sales generated by banner $=1.77 *$ additional sales generated by first screen), we computed expected profits of ISD types for 4 different levels of profit margin (20\%, 30\%, 40\% and 50\%; cf. Zhang and Wedel, 2008) and 3 different absolute placement costs (low, medium and high).

\section{<insert Figure 2>}

Figure 2 demonstrates that for medium and high placement costs (graphs b and c), first screen displays almost always outperform banner displays. Yet, in both cases, ISD only become profitable for relatively high margins $(30 \%$ and $50 \%$ in graph b for first screen and banner displays respectively) or do not become profitable at all (graph c). When placement costs are

\footnotetext{
${ }^{12}$ The fact that the average brand sales increase for banner displays is higher than the average brand sales increase for first screen displays is mainly driven by the significant effect of banner displays on category sales for 4 categories.

${ }^{13}$ Note that we make abstraction of costs other than placement costs (e.g., costs for designing the banner).
} 
relatively low (graph a), first screen displays - in spite of the lower brand sales increase may still be more profitable than banner displays when profit margins remain below a cut-off value (intersection point of both profit curves). At higher profit margins and absolute low placement costs, the higher sales increase of banners will more easily compensate the relatively (as compared to first screen displays) high placement costs. While based on average values of brand sales increase (average over all cases) and rude indicators of profit margins and placement costs, the example illustrates the major principles of the trade-off. In addition to the difference in sales increase (caused by the factors that were discussed above), differences in placement costs and profit margin levels have to be taken into account to determine whether first screen displays are more profitable than banner dipslays or vice versa.

\section{DISCUSSION}

Our results confirm that - like in B\&M stores - online ISD may substantially improve brand and category performance. Comparing market share and category sales effects, it is clear that (for most categories) the brand switching effect dominates the category sales effect. Online ISD have a significant positive effect in a much larger number of product categories at the brand market share level than at the category sales level. At the category sales level, no significant first screen effects could be found, while banner effects were only significant for 4 out of the 10 product categories. Therefore, our results seem to suggest that ISD predominantly stimulate brand switching within a category and are less effective in boosting primary demand. While contrary to our initial expectations, there are previous (B\&M based) studies which also show that in-store merchandising efforts especially affect brand choice decisions, and to a lesser extent primary demand (cf. Bell, Chiang, and Padmanabhan 1999; Foubert and Gijsbrechts 2007; Vilcassim and Jain 1991). In an online shopping context, an (additional) possible explanation for the near absence of category sales effects could be the 
convenience-oriented shopping attitude of online buyers who are less inclined to purchase categories they did not plan to buy beforehand.

At the same time, for part of the categories (mineral water, sparkling water, beer and at a $10 \%$ level also drinking yoghurt), banner displays did have a significant effect on category sales. A closer look at the online grocery store's organization reveals that there is a substantial difference in the composition of the product group pages, which contain more close substitutes for these 4 categories compared with the product group pages of the other 6 categories. For instance, while our focal category lager beer is positioned on the beer group page together with possible substitutes such as premium and other special beers, toilet paper is placed at the hygiene group page together with for example pocket handkerchiefs and nail polish remover. In the first case, banners (that are placed on top of the product group page) may stimulate between-category switching and in this way lead to a sales increase for the focal (featured) product category (e.g. switching from premium beer to lager beer when the latter is featured with a banner). Our results, therefore, might indicate that banner displays especially produce an increase in category sales for product categories that have more between-category substitution opportunities. To test these cross-category effects and to determine whether between-category switching is really a major reason for the increase in category sales we observed, more information would be needed on the substitution possibilities and on the sales evolution of other proximal categories.

While it is interesting to note that ISD may play an important role in online stores - especially at the brand choice level - our results also demonstrate that not all ISD types are equally effective in improving brand performance. Looking at differences between ISD types allows us to improve our understanding on the major determinants driving ISD effectiveness. 
Overall, first screen displays (comparable to store entrance displays) clearly appear to have the strongest effect on the featured brand's market share. They profit from a primacy effect and a strong(er) attention catching effect as a result of a more prominent on-screen position and no/limited competition from ISD for products of the same category. The overall brand market share effect, however, strongly depends on the attractiveness of the featured SKU and the marketing effectiveness of the brand as a whole.

Banner displays (comparable to end-of-aisle displays), in contrast, only have a significant effect on brand market share in a small number of product categories and - when significant have on average a smaller increase in brand market share than first screen displays. While over-reliance (in time and across brands) does not seem to be at play for this ISD type (see Table 2), possible explanations for a less dominant effect on brand market share are the midlevel location (in-between entrance and shopping zone of the online store), border-screen position and the absence of a direct purchase link. The amount of banners, the market share of the brand that received a banner as well as the number of SKUs of brands that were featured with a banner are roughly the same across categories and cannot be an explanatory factor of why the banner works on brand market share for only a subset of our categories. A factor that might have had a significant impact but for which we did not have extra information is the banner layout. Future research should investigate the impact of banner message and design. The effect of shelf tags (comparable to in-aisle displays), finally, tends to be smaller than the effect of first screen and banner displays and depends predominantly on the type of promotion and not so much on the presence of a tag announcing that there is a promotion. The differences between shelf tags with different promotions can to some extent be explained by a wear-out effect. Price cuts and free promotions are, for instance, used very often in the online store from which the data were obtained. Second, the effect of premium promotions strongly varies across categories (and brands), which may be explained by the type of product category 
but also by the attractiveness of the gift. Club points, finally, may have the advantage that they can be accumulated across categories, and for this reason may have a more substantial effect on product purchases. Yet, even when taking these considerations into account, the important conclusion remains that shelf tags may play an important role in attracting attention to promotional offers, but on their own, are not very successful in highlighting a specific brand/SKU and increasing its sales level.

Looking across categories and based upon our simulation results, it is interesting to observe that first screen and banner displays are especially effective for the top-selling categories (e.g. mineral water, soft drinks), which are purchased by a larger percentage of the online shoppers and/or on a more frequent basis. Overall, our results indicate that the effectiveness of online ISD may not only depend on the display type that is used, but also on product category characteristics, such as purchase frequency, penetration and differentiation. More information would be needed though (more categories and more information on category characteristics) in order to be able to perform a systematic analysis of these product-related differences on ISD effectiveness. The same holds for the differences in category sales effects across product categories, which could be a result of differences in between-category substitutability. As argued above, also here we would need more information to formally test this.

In conclusion, we can say that manufacturers - just like with traditional ISD - can use online ISD to highlight their products and stimulate purchase decisions, especially at the brand market share level for top-selling categories. In all categories, we found significant positive effects for at least one ISD type, with an average increase in brand market share of $16.65 \%$ and $9.09 \%$ for first screen and banner displays respectively. As expected, differences in effectiveness appear to be closely related to display type: first screen displays appear to have a 
clear advantage compared to banner displays, while shelf tag displays have virtually no effect on itself. In addition to display type, product characteristics also appear to affect the effectiveness of online ISD. A simple profitability analysis further reveals that the choice between banner and first screen displays not only depends on the increase in brand sales, but also on the brand's profit margin and the absolute and relative placement costs of the ISD. While high profit margins play in the advantage of display types with a strong(er) effect on brand sales, relatively low placement costs of less effective displays may compensate for the lower benefits they generate.

\section{LIMITATIONS AND FUTURE RESEARCH}

Clearly, this research exhibits limitations, and leaves ample opportunities for future research. For one, although we investigated several product categories, our findings should be verified in other (preferably non-grocery) product categories. One very interesting area for future research would be a context where customers are more likely to portray hedonic shopping behavior (e.g. when buying clothes, travel packages,...) and/or a context where they repeatedly visit a website over multiple days/weeks before purchasing (e.g. when buying nondurable goods such as cars, electronic appliances,...). In addition, we could only observe but not fully explain differences in ISD effectiveness across product categories. In many cases, ISD effects were significant for several product categories but the magnitude of the effect appeared to vary substantially across categories. Examining these differences in more detail requires a larger number of categories for which display effects can be tested, and could be an interesting topic for future research. In a similar vein, it would be very interesting to examine whether differences in category sales effects across categories can indeed be explained by cross-category effects. Unfortunately, due to a lack of information, we are not able to explore this in depth. 
Second, our analyses are limited to aggregate level models and immediate ISD effects. Using individual level models and/or investigating dynamic effects (e.g. frequency and timing) might constitute another interesting area for future research. In addition, focusing on other, more attitudinal outcome variables like brand recognition and recall might help in better understanding why not all ISD types are equally effective.

Third, in this research, we did not have access to information related to the message (e.g. copy) and design (e.g. color, graphic versus text, static versus dynamic) that would have allowed us to refine our (banner) results, neither were we able to estimate 'pure' shelf tag effects. It would therefore be interesting to do an (experimental) research to investigate these aspects in more detail.

Fourth, although costs attached to each ISD are undoubtedly an important factor for manufacturers to take into consideration when deciding which ISD to buy, we lacked information on other costs than placement costs (such as costs to design a banner) to do a complete and detailed profitability analysis. We recognize, however, that this would be a very interesting area to explore in future research.

Finally, despite our focus on real purchase decisions, we do not have an insight into the exact search and browsing path of the online customers. Investigating this with eye-tracking and/or click-stream data would also constitute an interesting avenue for future research. 
Table 1

Characteristics of online ISD: Effect on category sales and market share (part a) and categorization of the three ISD types (part b)

\begin{tabular}{|c|c|c|c|c|c|c|c|c|c|}
\hline \multicolumn{4}{|c|}{ Part a: Effect on category sales and brand market share } & \multicolumn{6}{|c|}{ Part b: Categorization of the three online ISD types } \\
\hline \multirow[t]{2}{*}{ Characteristic } & \multirow[t]{2}{*}{ Explanation } & \multicolumn{2}{|c|}{ Effect } & \multirow{2}{*}{\multicolumn{2}{|c|}{$\begin{array}{c}\text { First screen displays } \\
- \\
\text { STORE } \\
\text { DEPARTMENT } \\
\end{array}$}} & \multirow{2}{*}{\multicolumn{2}{|c|}{$\begin{array}{c}\text { Banner displays } \\
\text { - } \\
\text { PRODUCT GROUP }\end{array}$}} & \multirow{2}{*}{\multicolumn{2}{|c|}{$\begin{array}{c}\text { Shelf tag displays } \\
\text { - } \\
\text { CATEGORY LIST }\end{array}$}} \\
\hline & & $\begin{array}{l}\text { Cat. } \\
\text { Sales }\end{array}$ & $\begin{array}{l}\text { Brand } \\
\text { Market } \\
\text { Share }\end{array}$ & & & & & & \\
\hline Sequence & Order in hierarchy (early) & + & + & High-level page & + & Mid-level page & - & Low-level page & - \\
\hline Functionality & 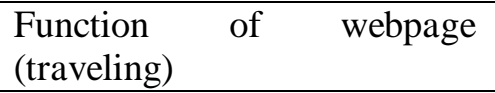 & - & - & Traveling zone & - & Traveling zone & - & Shopping zone & + \\
\hline \multirow[t]{2}{*}{ Visibility } & Page position (central) & + & + & Mid-screen & + & Border-screen & - & Mid-screen & + \\
\hline & Size (large) & + & + & Medium/Large & + & Medium/Large & + & Small & - \\
\hline Exclusivity & $\begin{array}{l}\text { Number of ads for } \\
\text { competitive brands }\end{array}$ & $\cap$ & - & $\begin{array}{ll}\text { No ads for } \\
\text { competitive } \\
\text { brands }\end{array}$ & + & $\begin{array}{l}\text { No ads for } \\
\text { competitive brands }\end{array}$ & + & $\begin{array}{l}\text { Several ads for } \\
\text { competitive brands }\end{array}$ & - \\
\hline Actionability & Direct purchase opportunity & + & + & Direct link & + & Indirect link & - & Direct link & + \\
\hline
\end{tabular}


Table 2

\section{Category overview and ISD descriptors}

\begin{tabular}{|c|c|c|c|c|c|c|c|c|c|}
\hline \multirow[t]{2}{*}{ Category } & \multirow{2}{*}{$\begin{array}{l}\text { Position in } \\
\text { top based } \\
\text { upon sales }\end{array}$} & \multirow{2}{*}{$\begin{array}{c}\text { \# of } \\
\text { brands in } \\
\text { category }\end{array}$} & \multirow{2}{*}{$\begin{array}{l}\text { Average } \\
\text { assort- } \\
\text { ment size }\end{array}$} & \multirow{2}{*}{$\begin{array}{c}\text { First } \\
\text { screen }^{*}\end{array}$} & \multirow[t]{2}{*}{ Banner $^{* *}$} & \multicolumn{4}{|c|}{ Shelf tag } \\
\hline & & & & & & Price cuts ${ }^{*}$ & Club points ${ }^{*}$ & Free promotions $^{*}$ & $\begin{array}{c}\text { Premium } \\
\text { promotions }\end{array}$ \\
\hline Mineral water & 1 & 8 & 26 & $7.7 \%(1)$ & $23 \%(3)$ & $23 \%(6)$ & $3.8 \%(1)$ & $87.5 \%(11)$ & $30 \%(3)$ \\
\hline Coke & 3 & 3 & 27 & $34.6 \%(6)$ & $19.2 \%(2)$ & $38.5 \%(10)$ & $3.8 \%(2)$ & $53.5 \%(6)$ & $50.8 \%(10)$ \\
\hline Sparkling water & 8 & 8 & 23 & $11.5 \%(2)$ & $11.5 \%(3)$ & $42.3 \%(10)$ & $3.8 \%(1)$ & $74.2 \%(11)$ & $21.7 \%(4)$ \\
\hline Beer & 9 & 3 & 18 & $19.2 \%(4)$ & $19.2 \%(3)$ & $46.2 \%(11)$ & $7.7 \%(2)$ & $93.3 \%(11)$ & $36.7 \%(7)$ \\
\hline Toilet paper & 10 & 3 & 17 & $53.8 \%(7)$ & $7.7 \%(2)$ & $50 \%(11)$ & $11.5 \%(4)$ & $66.7 \%(8)$ & n.r. \\
\hline Fabric softener & 24 & 7 & 34 & $19.2 \%(3)$ & $7.7 \%(3)$ & $38.5 \%(13)$ & $11.5 \%(4)$ & n.r. & $3.3 \%(1)$ \\
\hline Drinking yoghurt & 26 & 4 & 17 & $7.7 \%(2)$ & $7.7 \%(2)$ & $7.7 \%(3)$ & n.r. & n.r. & n.r. \\
\hline Shower soap & 37 & 9 & 49 & $23 \%(4)$ & $11.5 \%(3)$ & $30.8 \%(7)$ & $11.5 \%(4)$ & $86.7 \%(10)$ & n.r. \\
\hline Margarine & 43 & 13 & 36 & $15.4 \%(2)$ & $7.7 \%(2)$ & $38.5 \%(9)$ & $11.5 \%(3)$ & n.r. & n.r. \\
\hline Butter & 45 & 6 & 22 & $15.4 \%(3)$ & $7.7 \%(2)$ & $23 \%(4)$ & $11.5 \%(2)$ & n.r. & $10.8 \%(2)$ \\
\hline
\end{tabular}

Example interpretation for mineral water: this category is the top selling category for the online store and has on average 8 brands and 26 SKUs in its assortment. In $7.7 \%$ of the observation period ( 2 out of 26 months), at least one SKU was promoted via a first screen display and only 1 SKU received such an ISD (meaning that the same SKU was promoted twice with a first screen display). Banner displays were present during $23 \%$ of the observation period (6 out of 26 months), while only 3 brands were promoted with a banner display. Price cuts and club points occur for $23 \%$ and $3.8 \%$ in our observation period and 6 and 1 SKU, respectively. Free promotions are omnipresent: in as many as $87.5 \%$ in our observation period, there was at least 1 SKU in the category for which customers received a certain amount for free. Premium promotions occur for $30 \%$ of the time and 3 SKUs.

* $\%$ of months in the observation period that at least one SKU in the category was announced via a first screen display, or accompanied with a price cut, club point, free or premium promotion (number of SKUs that are promoted with a first screen, price cut, club point, free or premium promotion display)

$\%$ of months in the observation period that at least one banner display was used to promote all SKUs of a brand in the category (number of brands that are promoted with a banner display)

n.r. = not relevant (the category did not use this promotion type during our observation period) 
Table 3

Variables in the category sales and market share models

\begin{tabular}{|c|c|c|}
\hline Variable & Description & Model \\
\hline \multicolumn{3}{|c|}{ CatSales $_{t}=$ Weekly category sales (expressed in $\left.€\right), \mathrm{t}=1, \ldots, \mathrm{T}$} \\
\hline CatSales $_{t-1}$ & Lagged category sales & Category sales \\
\hline$D_{h t}$ & $\begin{array}{l}\text { Seasonal dummies, with } h=\text { index for holiday and } \\
\text { special event periods }(1, \ldots, \mathrm{H})\end{array}$ & Category sales \\
\hline$F S_{t}$ & $\begin{array}{l}\text { Dummy variable equal to } 1 \text { if at least one SKU in the } \\
\text { category was announced on the first screen at time } t\end{array}$ & Category sales \\
\hline$B A N_{t}$ & $\begin{array}{l}\text { Dummy variable equal to } 1 \text { if at least one brand in the } \\
\text { category was supported via a banner at time } t\end{array}$ & Category sales \\
\hline$P C_{t}$ & $\begin{array}{l}\text { Total amount of price reduction in the category at time } \\
\mathrm{t}\end{array}$ & Category sales \\
\hline$C P_{t}$ & $\begin{array}{l}\text { Total number of loyalty program points that could be } \\
\text { earned in the category at time } t\end{array}$ & Category sales \\
\hline$F P_{t}$ & $\begin{array}{l}\text { Dummy variable equal to } 1 \text { if at least one SKU } \\
\text { received a promotion in the form of 'buy } x \text {, get } y \text { for } \\
\text { free' in the category at time } t\end{array}$ & Category sales \\
\hline$P P_{t}$ & $\begin{array}{l}\text { Dummy variable equal to } 1 \text { if at least one SKU } \\
\text { received a gift in the category at time } t\end{array}$ & Category sales \\
\hline \multicolumn{3}{|c|}{$\begin{array}{l}m s_{s b, t}=\text { market share of SKU } \mathrm{s}(1, \ldots, \mathrm{S}) \text { of brand } \mathrm{b}(1, \ldots, \mathrm{B}) \text { at time } \mathrm{t}\left(=m s_{b, t} \times m s_{s \mid b, t}\right) \\
\text { with } \\
m_{b, t}=\text { market share of brand } \mathrm{b} \text { at time } \mathrm{t} \\
m_{s \mid b, t}=\text { market share of SKU s within brand } \mathrm{b} \text { at time } \mathrm{t}\end{array}$} \\
\hline$F S_{s b, t}$ & $\begin{array}{l}\text { Dummy variable equal to } 1 \text { if SKU s of brand } b \text { was } \\
\text { announced on the first screen at time } t\end{array}$ & $\begin{array}{l}\text { Market share, } \\
\text { lower level }\end{array}$ \\
\hline$P C_{s b, t}$ & $\begin{array}{l}\text { The amount of price reduction for SKU } s \text { of brand } b \text { at } \\
\text { time } t\end{array}$ & $\begin{array}{l}\text { Market share, } \\
\text { lower level }\end{array}$ \\
\hline$C P_{s b, t}$ & $\begin{array}{l}\text { The number of loyalty program points that could be } \\
\text { earned when purchasing SKU s of brand } b \text { at time } t\end{array}$ & $\begin{array}{l}\text { Market share, } \\
\text { lower level }\end{array}$ \\
\hline$F P_{s b, t}$ & $\begin{array}{l}\text { Dummy variable equal to } 1 \text { if SKU } \mathrm{s} \text { of brand } \mathrm{b} \\
\text { received a promotion in the form of 'buy } \mathrm{x} \text {, get } \mathrm{y} \text { for } \\
\text { free' }\end{array}$ & $\begin{array}{l}\text { Market share, } \\
\text { lower level }\end{array}$ \\
\hline$P P_{s b, t}$ & $\begin{array}{l}\text { Dummy variable equal to } 1 \text { if SKU } \mathrm{s} \text { of brand } \mathrm{b} \\
\text { received a gift }\end{array}$ & $\begin{array}{l}\text { Market share, } \\
\text { lower level }\end{array}$ \\
\hline$B A N_{b, t}$ & $\begin{array}{l}\text { Dummy variable equal to } 1 \text { if brand } b \text { was supported } \\
\text { via a banner }\end{array}$ & $\begin{array}{l}\text { Market share, } \\
\text { higher level }\end{array}$ \\
\hline$F S_{b, t}$ & $\begin{array}{l}\text { Dummy variable equal to } 1 \text { if an SKU of brand } b \text { was } \\
\text { announced on the first screen at time } t\end{array}$ & $\begin{array}{l}\text { Market share, } \\
\text { higher level }\end{array}$ \\
\hline$I V_{b, t}$ & $\begin{array}{l}\text { Inclusive value for brand at time } \mathrm{t} \text { (based on the } \\
\text { parameters of the lower level market share model) } \\
I V_{b, t}=\log \left(\sum_{s=1}^{S} \exp \left[\alpha_{s}+\sum_{m_{l}=1}^{M_{l}} \beta_{m_{l}} X_{m_{l} s b, t}\right]\right)\end{array}$ & $\begin{array}{l}\text { Market share, } \\
\text { higher level }\end{array}$ \\
\hline
\end{tabular}




\section{Table 4}

\section{Estimation results for the category sales model ${ }^{\text {a }}$}

\begin{tabular}{|c|c|c|c|c|c|c|c|c|c|c|}
\hline & Min. water & Coke & Spar. water & Beer & Toilet pap. & Fabric soft. & Drink yogh & Shower soap & Marg. & Butter \\
\hline \multirow[t]{2}{*}{ First screen display } & -0.083 & -0.018 & 0.049 & -0.035 & 0.065 & -0.065 & 0.035 & -0.012 & $-0.147^{*}$ & 0.007 \\
\hline & \multicolumn{10}{|c|}{ Stouffer: $Z_{c}=-0.82781 ; \mathrm{d}_{\mathrm{a}}=-0.04$} \\
\hline \multirow[t]{2}{*}{ Banner display } & $0.242^{\text {;**:\% }}$ & 0.122 & $0.251^{* * 17}$ & 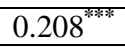 & -0.014 & -0.086 & $0.145^{*}$ & 0.000 & -0.045 & -0.045 \\
\hline & \multicolumn{10}{|c|}{ Stouffer: $Z_{c}=2.827266^{* * * *} ; \mathrm{d}_{\mathrm{a}}=0.16$} \\
\hline \multirow[t]{2}{*}{ Shelf tag display - price cut } & 0.066 & -0.125 & -0.133 & -0.068 & -0.049 & 0.064 & -0.096 & 0.028 & 0.210 & $0.234^{*}$ \\
\hline & \multicolumn{10}{|c|}{ Stouffer: $Z_{c}=0.336556 ; \mathrm{d}_{\mathrm{a}}=0.01$} \\
\hline \multirow[t]{2}{*}{ Shelf tag display - club point } & $0.168^{* *}$ & 0.037 & -0.069 & $0.267^{\text {**a*k}}$ & $0.266^{* * * *}$ & 0.172 & n.r. & $0.168^{*}$ & $0.266^{* *}$ & $0.255^{* * * *}$ \\
\hline & \multicolumn{10}{|c|}{ Stouffer: $Z_{c}=5,234984^{* * *} ; d_{a}=0.34$} \\
\hline \multirow[t]{2}{*}{ Shelf tag display - free } & -0.034 & 0.003 & -0.102 & -0.057 & 0.093 & n.r. & n.r. & -0.050 & n.r. & n.r. \\
\hline & \multicolumn{10}{|c|}{ Stouffer: $Z_{c}=0599598 ; \mathrm{d}_{\mathrm{a}}=-0.18$} \\
\hline \multirow[t]{2}{*}{ Shelf tag display - premium } & 0.008 & $0.165^{*}$ & -0.052 & $0.207^{* *}$ & n.r. & 0.023 & n.r. & n.r. & n.r. & $-0.327^{* * *}$ \\
\hline & \multicolumn{10}{|c|}{ Stouffer: $Z_{c}=1,203543 ; d_{a}=0.10$} \\
\hline \multirow[t]{2}{*}{ Lagged category sales } & $0.339^{* * * *}$ & $0.165^{* *}$ & $0.269^{\text {**** }}$ & $0.260^{* * * *}$ & 0.042 & 0.066 & $0.444^{* * * *}$ & 0.084 & $0.387^{* * * *}$ & $0.504^{* * * * *}$ \\
\hline & \multicolumn{10}{|c|}{ Stouffer: $Z_{c}=10,09258^{* * *} ; \mathrm{d}_{\mathrm{a}}=0.56$} \\
\hline \multirow[t]{2}{*}{ Summer } & $-0.294^{* * * *}$ & $-0.319^{\text {***** }}$ & -0.132 & -0.042 & $-0.467^{* * * *}$ & $-0.432^{* * * * *}$ & $-0.328^{* * * *}$ & $-0.303^{* * * *}$ & $-0.184^{* *}$ & $-0.137^{*}$ \\
\hline & \multicolumn{10}{|c|}{ Stouffer: $Z_{c}=-10.2938^{* * * * *} ; \mathrm{d}_{\mathrm{a}}=-0.60$} \\
\hline \multirow[t]{2}{*}{ Eastern } & $-0.126^{*}$ & -0.084 & -0.088 & $-0.196^{* *}$ & -0.150 & $-0.207^{* * *}$ & $-0.265^{* \ldots *}$ & $-0.183^{* *}$ & -0.060 & -0067 \\
\hline & \multicolumn{10}{|c|}{ Stouffer: $Z_{c}=-4.73409^{* * * *} ; \mathrm{d}_{\mathrm{a}}=-0.32$} \\
\hline \multirow[t]{2}{*}{ New Year/Christmas } & $-0.248^{* * * *}$ & $-0.384^{* * * * *}$ & $-0.346^{* * * *}$ & $-0.241^{* * * * *}$ & $-0.356^{* * 6}$ & $-0.309^{* * *}$ & -0.067 & -0.131 & -0.092 & $-0.155^{* * *}$ \\
\hline & \multicolumn{10}{|c|}{ Stouffer: $Z_{c}=-10.109^{* * *} ; \mathrm{d}_{\mathrm{a}}=-0.55$} \\
\hline \multirow[t]{2}{*}{ Mid Term } & $-0.146^{* *}$ & -0.073 & -0.117 & $-0.102^{* *}$ & $-0.300^{* * * * 1}$ & $-0.173^{* *}$ & -0.054 & -0.009 & -0.035 & -0.086 \\
\hline & \multicolumn{10}{|c|}{ Stouffer: $Z_{c}=-4.408008^{* * *} ; \mathrm{d}_{\mathrm{a}}=-0.28$} \\
\hline Adjusted R $\mathbf{R}^{2}$ & 0.481 & 0.297 & 0.368 & 0.358 & 0.464 & 0.286 & 0.544 & 0.143 & 0.431 & 0.596 \\
\hline
\end{tabular}


Table 5

\section{Estimation results for the hierarchical market share model ${ }^{\text {a }}$}

\begin{tabular}{|c|c|c|c|c|c|c|c|c|c|c|}
\hline & Min. water & Coke & Spar. water & Beer & Toilet pap. & Fabric soft. & Drink yogh & Shower soap & Marg. & Butter \\
\hline \multicolumn{11}{|c|}{ Hierarchical market share model - Stage 1: SKU level } \\
\hline \multirow[t]{2}{*}{$\begin{array}{r}\text { First screen display } \\
\text { Positive, significant }(5 \%) \\
\text { Not significant } \\
\text { Negative significant }(5 \%)\end{array}$} & $\begin{array}{l}1 \\
0 \\
0\end{array}$ & $\begin{array}{l}1 \\
2 \\
0\end{array}$ & $\begin{array}{l}1 \\
1 \\
0\end{array}$ & $\begin{array}{l}2 \\
1 \\
0\end{array}$ & $\begin{array}{l}2 \\
0 \\
0\end{array}$ & $\begin{array}{l}1 \\
0 \\
0\end{array}$ & $\begin{array}{l}1 \\
1 \\
0\end{array}$ & $\begin{array}{l}1 \\
1 \\
0\end{array}$ & $\begin{array}{l}1 \\
0 \\
0\end{array}$ & $\begin{array}{l}1 \\
0 \\
0\end{array}$ \\
\hline & \multicolumn{10}{|c|}{ Stouffer: $Z_{c}=11.47828^{* * * *} ; \mathrm{d}_{\mathrm{a}}=0.58$} \\
\hline \multirow[t]{2}{*}{$\begin{array}{r}\text { Shelf tag display - price cut } \\
\text { Positive, significant (5\%) } \\
\text { Not significant } \\
\text { Negative significant }(5 \%)\end{array}$} & $\begin{array}{l}0 \\
3 \\
0\end{array}$ & $\begin{array}{l}0 \\
0 \\
2\end{array}$ & $\begin{array}{l}1 \\
3 \\
0\end{array}$ & $\begin{array}{l}0 \\
2 \\
1\end{array}$ & $\begin{array}{l}0 \\
1 \\
0\end{array}$ & $\begin{array}{l}1 \\
3 \\
0\end{array}$ & $\begin{array}{l}0 \\
1 \\
0\end{array}$ & $\begin{array}{l}0 \\
3 \\
0\end{array}$ & $\begin{array}{l}1 \\
2 \\
0\end{array}$ & $\begin{array}{l}0 \\
2 \\
0\end{array}$ \\
\hline & \multicolumn{10}{|c|}{ Stouffer: $Z_{c}=0.81382 ; \mathrm{d}_{\mathrm{a}}=0.03$} \\
\hline \multirow[t]{2}{*}{$\begin{array}{r}\text { Shelf tag display - club point } \\
\text { Positive, significant }(5 \%) \\
\text { Not significant } \\
\text { Negative significant }(5 \%)\end{array}$} & $\begin{array}{l}0 \\
1 \\
0\end{array}$ & $\begin{array}{l}0 \\
1 \\
0\end{array}$ & $\begin{array}{l}0 \\
1 \\
0\end{array}$ & $\begin{array}{l}0 \\
2 \\
0\end{array}$ & $\begin{array}{l}0 \\
1 \\
0 \\
\end{array}$ & $\begin{array}{l}0 \\
2 \\
0 \\
\end{array}$ & n.r. & $\begin{array}{l}1 \\
1 \\
0\end{array}$ & $\begin{array}{l}0 \\
1 \\
0\end{array}$ & $\begin{array}{l}1 \\
0 \\
1\end{array}$ \\
\hline & \multicolumn{10}{|c|}{ Stouffer: $Z_{c}=3.716902^{* * * *} ; d_{a}=0.14$} \\
\hline \multirow[t]{2}{*}{$\begin{array}{r}\text { Shelf tag display - free } \\
\text { Positive, significant (5\%) } \\
\text { Not significant } \\
\text { Negative significant (5\%) }\end{array}$} & $\begin{array}{l}2 \\
4 \\
1\end{array}$ & $\begin{array}{l}0 \\
0 \\
1\end{array}$ & $\begin{array}{l}0 \\
3 \\
1\end{array}$ & $\begin{array}{l}0 \\
1 \\
2\end{array}$ & $\begin{array}{l}1 \\
1 \\
0\end{array}$ & n.r. & n.r. & $\begin{array}{l}0 \\
1 \\
1\end{array}$ & n.r. & n.r. \\
\hline & \multicolumn{10}{|c|}{ Stouffer: $Z=-0.61198 ; d_{a}=0.12$} \\
\hline \multirow[t]{2}{*}{$\begin{array}{r}\text { Shelf tag display - premium } \\
\text { Positive, significant }(5 \%) \\
\text { Not significant } \\
\text { Negative significant }(5 \%)\end{array}$} & $\begin{array}{l}0 \\
3 \\
0\end{array}$ & $\begin{array}{l}0 \\
2 \\
0\end{array}$ & $\begin{array}{l}1 \\
2 \\
0\end{array}$ & $\begin{array}{l}1 \\
1 \\
0\end{array}$ & n.r. & $\begin{array}{l}0 \\
1 \\
0\end{array}$ & n.r. & n.r. & n.r. & $\begin{array}{l}0 \\
2 \\
0\end{array}$ \\
\hline & \multicolumn{10}{|c|}{ Stouffer: $Z_{c}=1.712101^{* *} ; \mathrm{d}_{\mathrm{a}}=0.10$} \\
\hline \multicolumn{11}{|c|}{ Hierarchical market share model-Stage 2: Brand level } \\
\hline \multirow[t]{2}{*}{ First screen display } & 0.033 & 0.043 & -0.042 & $0.162^{\text {*:*k }}$ & $0.338^{* * * *}$ & -0.498 & $0.183^{*}$ & 0.118 & -0.071 & -0.012 \\
\hline & \multicolumn{10}{|c|}{ Stouffer: $Z_{c}=3.159153^{*, * * *} ; d_{a}=0.23$} \\
\hline \multirow[t]{2}{*}{ Banner display } & $0.105^{* * * *}$ & $0.106^{* * *}$ & 0.090 & -0.082 & -0.060 & -0.131 & $0.229^{* * * *}$ & -0.002 & $0.311^{\text {*** }}$ & 0.053 \\
\hline & \multicolumn{10}{|c|}{ Stouffer: $Z_{c}=2.804759^{*, * * *} ; \mathrm{d}_{\mathrm{a}}=0.20$} \\
\hline \multirow[t]{2}{*}{ Inclusive value (1- $-\sigma)$} & $0.106^{*}$ & $0.958^{* * * *}$ & $0.542^{* * * *}$ & $0.464^{* * * *}$ & $0.103^{* * * *}$ & $0.758^{* * * *}$ & $0.659^{* * * *}$ & $0.829^{* * * *}$ & $0.191^{* * * *}$ & $0.858^{\text {**** }}$ \\
\hline & \multicolumn{10}{|c|}{ Stouffer: $Z=14.6267^{* * * *} ; d_{a}=1.12$} \\
\hline
\end{tabular}


Table 6

Simulation results ${ }^{a}$

\begin{tabular}{|l|c|c|c|}
\hline & Category sales $\left(\right.$ CatSales $\left._{t}\right)$ & Brand market share $\left(m s_{b, t}\right)$ & Brand sales increase \\
\hline $\begin{array}{l}\text { First screen } \\
\text { display }\end{array}$ & $\begin{array}{c}\text { Average \% increase }=0 \% \\
\text { (only significant cases: } 0 \%)\end{array}$ & $\begin{array}{c}\text { Average } \% \text { increase }=16.65 \% \\
\text { (only significant cases: } 25.73 \%) \\
\text { [Range: } 0.68 \%-106.29 \%]\end{array}$ & $\begin{array}{c}\text { Average increase in } €=215.35 € \\
\text { (only significant cases: } 276.87 €) \\
\text { [Range: } 2.57 €-708.76 €]\end{array}$ \\
\hline Banner display & $\begin{array}{c}\text { Average \% increase }=6.63 \% \\
\text { (only significant cases: } 15.76 \%) \\
\text { [Range: } 13.40 \%-17.87 \%]\end{array}$ & $\begin{array}{c}\text { Average \% increase }=9.09 \% \\
\text { (only significant cases: } 12.88 \%) \\
\text { [Range: } 0.44 \%-33.67 \%]\end{array}$ & $\begin{array}{c}\text { Average increase in } €=380.47 € \\
\text { (only significant cases: } 595.52 €) \\
\text { [Range: } 32.04 €-2,277.14 €]\end{array}$ \\
\hline
\end{tabular}


Figure 1

Overview of online ISD characteristics and their effect on purchase behavior

ISD characteristic

Mediating effect

Purchase behavior

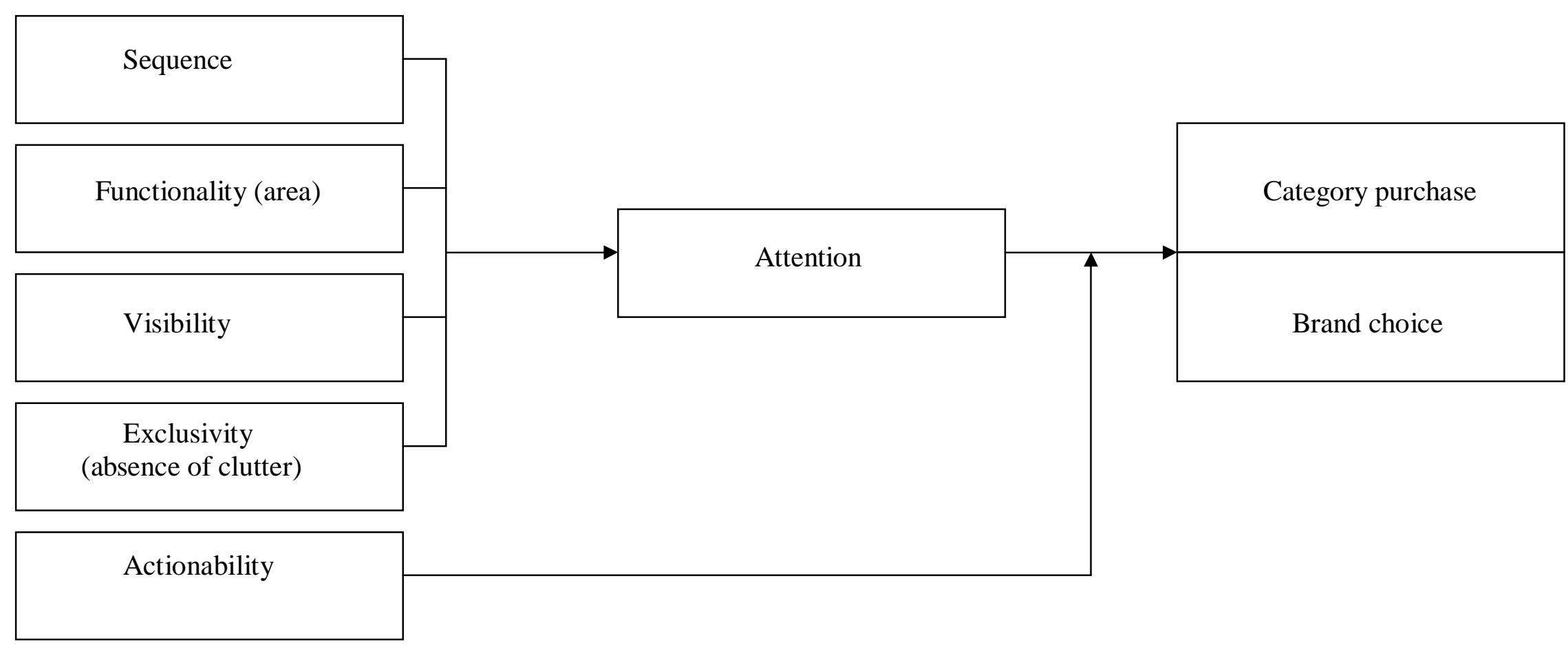


Figure 2

\section{Profitability analyses}

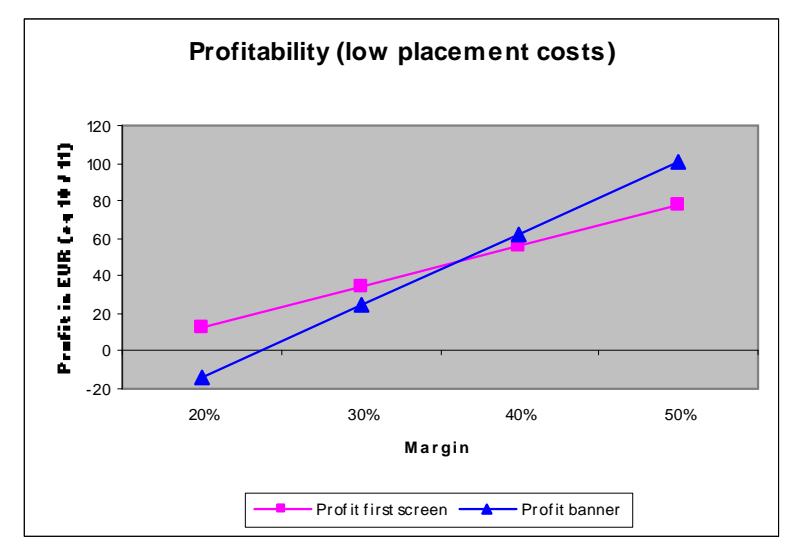

(a) low absolute placement cost

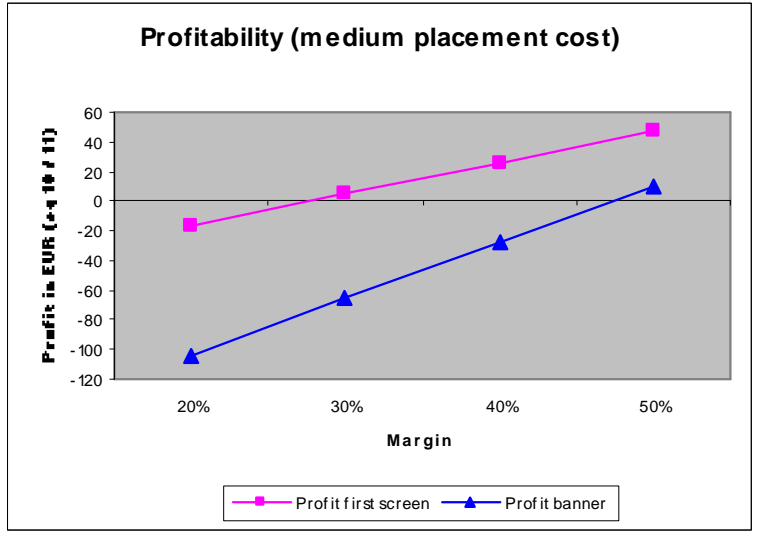

(b) medium absolute placement cost

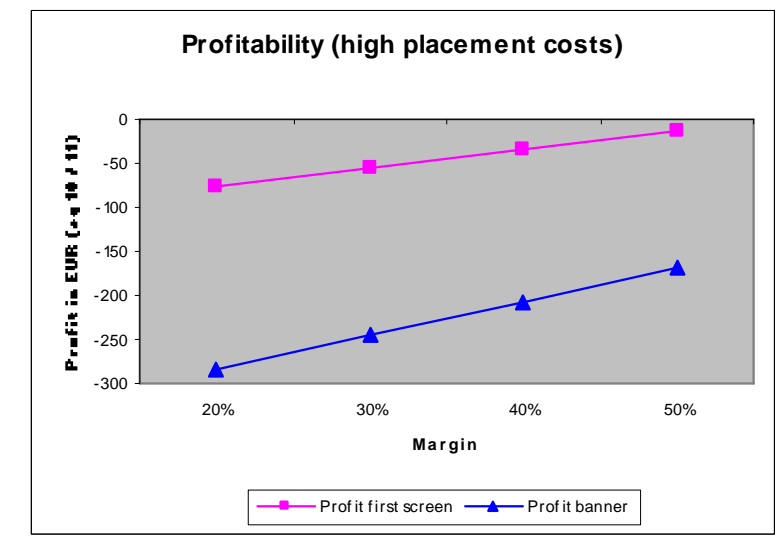

(c) high absolute placement cost 


\section{Appendix A}

Visual representation of different online ISD types

1. First screen display

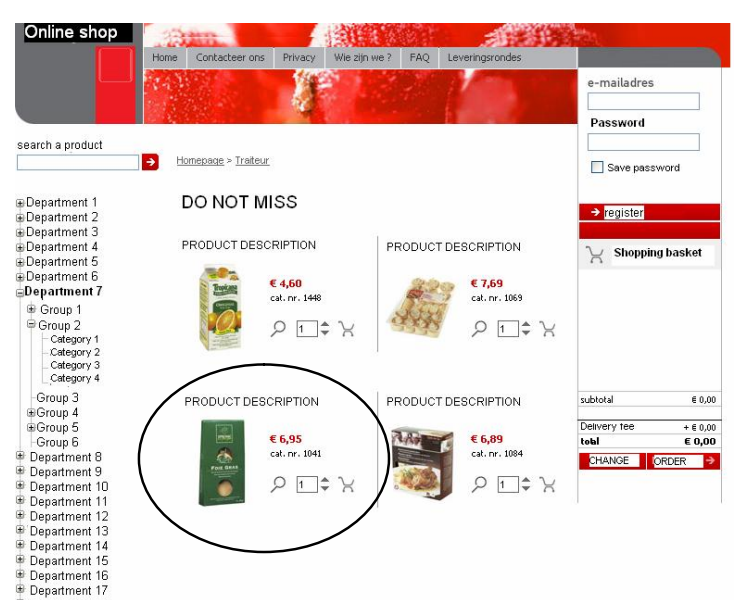

(Store department page)
2. Banner display

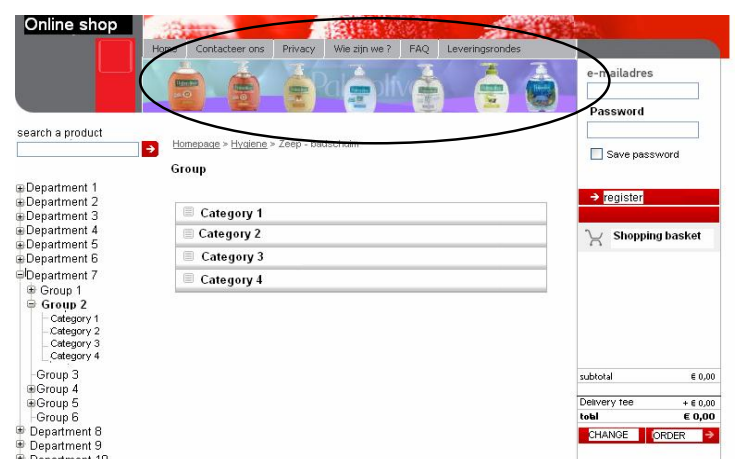

(Product group page)
3. Shelf tag display

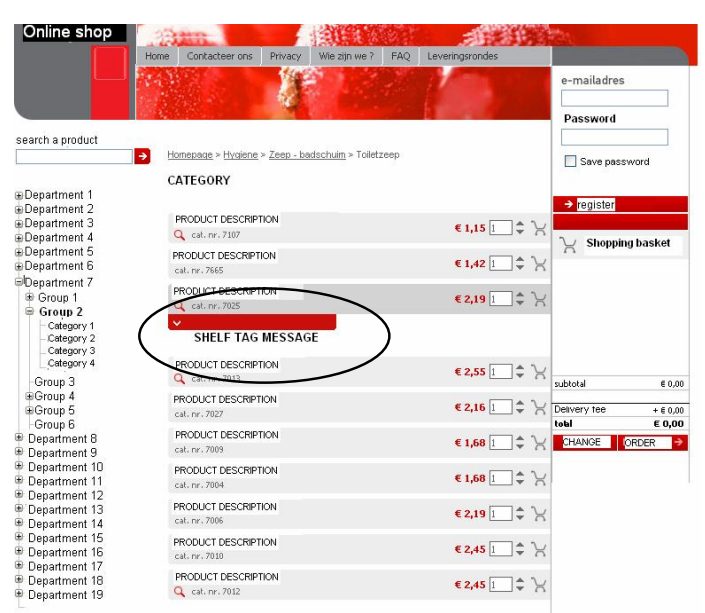

(Category list page) 


\section{REFERENCES}

Anderson, Eric and Duncan T. Simester (2001), “Are Sales Signs Less Effective When More Products Have Them?," Marketing Science, 20 (2), 121-143.

Bell, David R., Jeongwen Chian, and V. Padmanabhan (1999), “The Decomposition of Promotional Response: An Empirical Generalization," Marketing Science, 18 (4), 504526.

Bemmaor, Albert C. and Dominique Mouchoux (1991), "Measuring the Short-Term Effect of In-Store Promotion and Retail Advertising on Brand Sales: A Factorial Experiment," Journal of Marketing Research, 28 (2), 202-214.

Breugelmans, Els, Katia Campo, and Els Gijsbrechts (2006), "Opportunities for Active Stock-Out Management in Online Stores: The Impact of Stock-Out Policy on Online Stock-Out Reactions," Journal of Retailing, 82 (3), 215-228.

----, ----, and ---- (2007), “Shelf Sequence and Proximity Effects on Online Grocery Choices," Marketing Letters, 18 (1/2), 117-133.

Chan, Tat, Chakravarthi Narasimhan, and Qin Zhang (2008), "Decomposing Promotional Effects with a Dynamic Structural Model of Flexible Consumption Preview," Journal of Marketing Research, 45 (4), 487-498. 
Chandon, Jean L., Mohamed S. Chtourou, and David R. Fortin (2003), "Effects of Configuration and Exposure Levels on Responses to Web Advertisements," Journal of Advertising Research, 43 (2), 217-229.

Chandon, Pierre, Wesley J. Hutchinson, Eric Bradlow, and Scott H. Young (2007), "Measuring the Value of Point-of-Purchase Marketing with Commercial Eye-Tracking Data,” INSEAD Business School Research Paper No. 2007/22/MKT/ACGRD.

Cho, Chang-Hoan and Hongsik, J. Cheon (2004), "Why do People Avoid Advertising on the Internet," Journal of Advertising, 33 (4), 89-97.

Cohen, Jacob (1977). Statistical power analysis for the behavioral sciences (revised edition). New York: Academic Press.

Curhan, Ronald C. (1974), "The Effects of Merchandising and Temporary Promotional Activities on the Sales of Fresh Fruits and Vegetables in Supermarkets," Journal of Marketing Research, 11 (3), 286-294.

DelVecchio, Devon, Shanker H. Krishnan, and Daniel C. Smith (2007), “Cents or Percent? The Effects of Promotion Framing on Price Expectations and Choice," Journal of Marketing, 71 (3), 158-170. 
Desmet, Pierre and Valerie Renaudin (1998), "Estimation of Product Category Sales Responsiveness to Allocated Shelf Space," International Journal or Research in Marketing, 15 (5), 443-457.

Drèze, Xavier, Stephen Hoch, and Mary E. Purk (1994), "Shelf Management and Space Elasticity," Journal of Retailing, 70 (4), 301-326.

East, Robert, Vicki Eftichiadou, and Michael Williamson (2003), "Research note: Pointof-Purchase Display and Brand Sales," International Review of Retail, Distribution and Consumer Research, 13(1), 127-135.

Foekens, Eijte W., Peter S.H. Leeflang, and Dick R. Wittink (1997), "Hierarchical versus Other Market Share Models for Markets with Many Items," International Journal of Research in Marketing, 14 (4), 359-378.

Foubert, Bram and Els Gijsbrechts (2007), "Shopper Response to Bundle Promotions for Packaged Goods,” Journal of Marketing Research, 44 (4), 647-662.

Gijsbrechts, Els, Katia Campo, and Tom Goossens (2003), “The Impact of Store Flyers on Store Traffic and Store Sales: A Geo-Marketing Approach,” Journal of Retailing, 79 (1), 1-16. 
Hanssens, Dominique M., Leonard J. Parson, and Randall L. Schultz (2001), Market Response Models: Econometric and Time Series Analysis, Kluwer Academic Publishers.

Howard, Daniel J. and Roger A. Kerin (2006), "Broadening the Scope of Reference Price Advertising Research: A Field Study of Consumer Shopping Involvement," Journal of Marketing, 70 (3), 185-204.

Hoyer, Wayne D. (1984), “An Examination of Consumer Decision Making for a Common, Repeat-Purchase Product," Journal of Consumer Research, 11 (3), 822-829.

Inman, Jeffrey J., Leigh McAlister, and Wayne D. Hoyer (1990), "Promotion Signal: Proxy for a Price Cut?," Journal of Consumer Research, 17 (1), 74-81.

Kumar, V. and Robert P. Leone (1988), "Measuring the Effect of Retail Store Promotions on Brand and Store Substitution,” Journal of Marketing Research, 25 (2), 178-185.

Larson, Jeffrey S., Eric Bradlow, and Peter S. Fader (2005), “An Exploratory Look at Supermarket Shopping Paths," International Journal of Research in Marketing, 22 (4), $395-414$.

Liljenwall, Robert (2004), The Power of Point-of-Purchase Advertising: Marketing at Retail. Washington DC: Point-of-Purchase Advertising International. 
Lohse, Gerald L. (1997), “Consumer Eye Movement Patterns on Yellow Pages Advertising," Journal of Advertising, 26 (1), 61-73.

McKinnon, Gary F., Patrick J. Kelly, and Robison E. Doyle (1981), "Sales Effects of Point-of-Purchase In-Store Signing,” Journal of Retailing, 57 (2), 49-63.

Petty, Richard E. and John T. Cacioppo (1986), From Communication and Persuasion: Central and Peripheral Routes to Attitude Change. New York: Springer-Verlag.

Pieters, Rick G.M. and Tammo H.A. Bijmolt (1997), "Consumer Memory for Television Advertising: A Field Study of Duration, Serial Position, and Competition Effects," Journal of Consumer Research, 23 (4), 362-372.

Rosenthal, Robert (1991), Meta analytic procedures for social research. Applied Social Research Methods Series. Beverly Hills: Sage Publications.

Rossiter, John R. and Larry Percy (1998), Advertising communications and promotion management. Boston: McGraw-Hill.

Spaeth, Jim (2004), "Post-Promotion Evaluation,” Point of Purchase Advertising International. [available at http://www.allbusiness.com/retail-trade/4250967-1.html] 
Tellis, Gerard J. (1998), Advertising and Sales Promotion Strategy. Reading, MA:

Addison-Wesley.

Vilcassim, Naufel J. and Dipak C. Jain (1991), "Modeling Purchase-Timing and BrandSwitching Behavior Incorporating Explanatory Variables and Unobserved Heterogeneity," Journal of Marketing Research, 28 (1), 29-41.

Vrechopoulos, Adam P., Robert M. O’Keefee, Georgios I. Doukidis, and George J. Siomkos (2004), "Virtual Store Layout: An Experimental Comparison in the Context of Grocery Retail," Journal of Retailing, 80 (1), 13-23.

Wolf, Fredric (1986), Meta analysis: Quantitative methods for research synthesis. Beverly Hills, CA: Sage Publications.

Zhang, Jie and Michel Wedel (2008), "The Effectiveness of Customized Promotions in Online and Offline Stores," Journal of Marketing Research, forthcoming. 